\title{
A centuries old problem in nephtheid taxonomy approached using DNA data (Coelenterata: Alcyonacea)
}

\author{
L.P. van Ofwegen, D.S.J. Groenenberg \\ Nationaal Natuurhistorisch Museum Naturalis, P.O. Box 9517, 2300 RA Leiden, The Netherlands, ofwegen@ \\ naturalis.nl
}

Key words: soft corals, Octocorallia, Nephtheidae, Dendronephthya, Litophyton, Neospongodes, Nephthea, Stereonephthya, taxonomy, internal transcribed spacer I and II, Indo-Pacific

\begin{abstract}
The current centuries old classification of the family Nephtheidae is still mostly based on colony morphology. In this family the Indo-Pacifc genera Litophyton, Nephthea, Dendronephthya and Stereonephthya, and the Atlantic genus Neospongodes form a complex mix of closely related, poorly described species which cannot be recognized using only colony morphology. Attempts with the more modern approach of comparing skeleton composition (sclerites) have been only partly successful because of the extreme variation of sclerite forms present in these genera. The genus Chromonephthea Van Ofwegen, 2005, introduced for several species previously assigned to Dendronephthya, Nephthea and Stereonephthya, was established with sclerite morphology, but the true generic status of the majority of the nominal species of these genera remained unresolved. In an attempt to clarify the phylogenetic relationships between Litophyton, Nephthea, Stereonephthya and Chromonephthea fourteen specimens, unidentified but certainly belonging to these genera, have been used in molecular analyses. All analyses supported two clades, which could be related to the shape of the sclerites present in the polyp stalks. One clade contained the specimens with characters for Stereonephthya along with the Chromonephthea specimen as a sister group. The other clade had a 'true' Nephthea and Litophyton together with the specimens that could not be placed in any particular genus using the old classification criteria. The consequences of these results for nephtheid classification are discussed.
\end{abstract}

\section{Contents}

Introduction 153

Short history of the genera Litophyton, Nephthea, Stereonephthya, Dendronephthya and Neospongodes .......... 154

The modern classification …..................................................... 154

Short descriptions of the material used .................................... 155

Methods ............................................................................. 173

Sequence variation …...................................................... 173

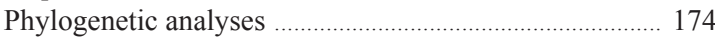

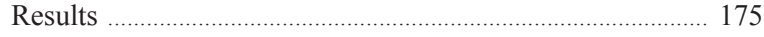

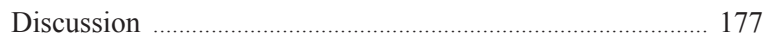

Acknowledgements ................................................................. 178

References …...................................................................... 178

\section{Introduction}

After the Alcyoniidae Lamouroux, 1812, the family Nephtheidae Gray, 1862, is the most common soft coral family in tropical Indo-Pacific waters regarding numbers of genera and species. The often colourful colonies of nephtheid species can form large aggregates by asexual reproduction. Most species have treeor bush-like colonies and can be found from low tide to the abyss.

In the tropical Indo-Pacific twelve nominal genera are currently assigned to the Nephtheidae: Litophyton Forskål, 1775; Nephthea Audouin, 1828; Lemnalia Gray, 1868; Capnella Gray, 1869; Scleronephthya Studer, 1887; Dendronephthya Kükenthal, 1905; Stereonephthya Kükenthal, 1905; Paralemnalia Kükenthal, 1913; Umbellulifera Thomson and Dean, 1931; Leptophyton Van Ofwegen and Schleyer, 1997; Pacifiphyton Williams, 1997; and Chromonephthea Van Ofwegen, 2005. On the basis of a recent molecular phylogenetic study, McFadden et al. (2006) suggest that less genera are involved, because in their analysis Lemnalia and Paralemnalia form a clade with the alcyoniid Rhytisma Alderslade, 2000, and Capnella a clade with the paralcyoniid genera Paralcyonium Milne Edwards and Haime, 1850, and Studeriotes Thomson and Simpson, 1909.

In the Atlantic, the Antarctic and the colder waters of the Pacific an additional seven genera have been described in the nephtheids, one of which, viz. the 
tropical Atlantic Neospongodes Kükenthal, 1903, resembles the Indo-Pacific Stereonephthya regarding sclerites and colony form.

To date, Litophyton, Nephthea, Dendronephthya and Stereonephthya form a complex mix of closely related but poorly described species. Hence, around 1990, the first author started a morphological revision of the genera Litophyton, Nephthea, and Stereonephthya, also including a number of species assigned to Dendronephthya and the monotypic Atlantic genus Neospongodes. A first outcome of this study was the description of the genus Chromonephthea Van Ofwegen, 2005, for several species previously assigned to Dendronephthya, Nephthea and Stereonephthya.

In an attempt to clarify the phylogenetic relationships between some species that are actually classified with Litophyton, Nephthea, Stereonephthya, and Chromonephthea, a few molecular markers previously tested with octocorals were used. By doing so the status of the morphological characters nowadays employed in nephtheids can be compared with the resulting phylogeny.

\section{Short history of the genera Litophyton, Nephthea, Stereonephthya, Dendronephthya and Neospon- godes}

Forskål (1775) described the first Indo-Pacific nephtheid, Litophyton arboreum, from an unknown locality in the Red Sea. According to modern standards his description was inadequate. The material on which he based his description is lost.

Andouin (1828), referring to plates published by Savigny (1817), erected two additional nephtheid genera from the Red Sea, viz. Ammothea for A. virescens, and Nephthea, for N. chabrolii. As far as known, the material on which these two taxa were based has been also lost.

After this a period followed in which numerous nominal genera and subgenera were introduced or synonymized. Many new species were described, and others were moved from genus to genus.

Kükenthal $(1903,1905)$ made a revision of the nephtheids in which he abandoned Ammothea and described three more genera, Neospongodes Kükenthal, 1903, Dendronephthya Kükenthal, 1905, and Stereonephthya Kükenthal, 1905, all of which without assigning a type species. He presented the following classification, which is still used by most authors (for details of terminology, see Bayer et al. (1983)):
Polyps without a supporting bundle, polyps in catkins . Litophyton

Polyps with a supporting bundle, polyps in catkins Nephthea

Polyps with a supporting bundle, polyps in bundles or alone, no axis ... Stereonephtya Polyps with a supporting bundle, polyps in bundles or alone, internal axis of spindles Neospongodes

Polyps with a supporting bundle, polyps in bundles Dendronephthya

Dendronephthya is subdivided into three groups:

Sparsely arborescent branching colonies with slender ramifications, and polyps in small insignificant bundles Divaricata-group

Close short branching colonies where the polyp bundles are assembled, forming large, distinctly rounded bunches Glomerata-group

Polyp bundles closely arranged at the same level on the ends of the twigs, forming numerous umbrella-like crowns. Several umbrella-like sections may combine to form hemispheres Umbellata-group

Later on, Utinomi (1954) designated Nephthea savignyi Ehrenberg, 1834, as the type species of Dendronephthya and Stereonephthya papyracea Kükenthal, 1905, as the type species of Stereonephthya. He characterized Stereonephthya as follows: (1) supporting bundles of the polyps well developed, each with a strong projecting tip, (2) ventral side of the polyp stalk with small tiny rods, (3) polyp heads usually hanging down from their stalks, like a campanulate flower, (4) dorsal points strong, ventral points poorly supported or lacking.

Finally, Verseveldt (1983) re-examined Neospongodes atlantica and $N$. bahiensis, the two species Kükenthal (1903) referred to Neospongodes. Verseveldt designated a lectotype for $N$. atlantica and synonymized $N$. bahiensis with $N$. atlantica. He changed the diagnosis of Neospongodes to "Tree-like, very flabby nephtheids, with a slender stalk and stem. Polyps isolated and scattered on thin branches and twigs, with supporting bundles".

\section{The modern classification}

Re-examination of most of the type specimens of the species described in Litophyton, Nephthea and Stereonephthya showed that the characters used by Kükenthal (1903, 1905) may be problematic: 
1) The presence of a supporting bundle is not as straightforward a character as suggested by Kükenthal (1905). In the re-examined holotype of Litophyton acutifolium Kükenthal, 1913, most polyps are without a trace of such a bundle, as diagnosed for Litophyton, but a few polyps clearly show one. Moreover, specimens identified by Verseveldt (1966) as L. arboreum Forskål, 1775, have a supporting bundle, though Verseveldt reported it as missing. Re-examination of the polyps of this species brought many small, irregularly arranged rods to light, but quite a few polyps show larger sclerites at the dorsal side, which in our opinion is a clear supporting bundle.

2) All nephtheids have an accumulation of polyps on the end of their branches. Species of Dendronephthya with polyps united in small bundles clearly differ from other nephtheids with respect to this character, but the presence or absence of catkins seems to rely on the amount of contraction after collection. Species with small polyps with less sclerites simply contract more easily to form catkins.

3) Polyps in bundles or single. This character is very difficult to check in Stereonephthya and species of the Divaricata group of Dendronephthya, as both have very crowded polyps at the end of the branches. Using the presence of small rods in the polyp stalk, as suggested by Utinomi (1954), the type species of Dendronephthya, D. savignyi (Ehrenberg, 1834) falls within Stereonephthya.

4) The presence of small rods in the polyp stalk in species of Stereonephthya. Examination of Dendronephthya species of both the Glomerata and the Umbellata group showed that polyps never have small rods in the polyp stalk, which are present in several species of the Divaricata group. Moreover, many species assigned to Nephthea also show small rods in the polyp stalk.

5) According to Verseveldt (1983), the differences between Neospongodes and Stereonephthya are mini$\mathrm{mal}$, in that the latter has rigid colonies and $\mathrm{Ne}$ ospongodes flabby ones, which cannot be used to differentiate between genera convincingly.

6) Kükenthal $(1903,1905)$ completely ignored the sclerite characters of other parts of the colony. Using those the first author recognized Chromonephthea Van Ofwegen, 2005.

\section{Short descriptions of the material used}

The material used for DNA analyses is briefly characterized. Because of the above mentioned problems with the classification and the still ongoing morphological revision, the species of Litophyton, Nephthea, and Stereonephthya could not be identified. However, we do mention 'true' Litophyton and Nephthea following Kükenthal's classification.

1) RMNH Coel. 32053, MAL.05, one colony, Fauna Malesiana Maluku Expedition, 1996, Indonesia, Ambon, N coast, Manuala beach, W of Hila, $03^{\circ} 35^{\prime} \mathrm{S}$ $128^{\circ} 05^{\prime} \mathrm{E}$, gradually sloping sandy bottom, with scattered coral heads, snorkeling and diving, depth -10 m, 7.xi.1996; 'true' Litophyton.

The flabby colony is $20 \mathrm{~cm}$ long with several stems arising from a common base (Fig. 1a). The polyps are grouped at the end of the branches, a configuration described in literature as slender catkins. Its sclerites are typical for a species of Litophyton. The polyps and end branches have very few sclerites (Fig. 2a). The irregularly arranged polyp sclerites are small rods, which are up to $0.07 \mathrm{~mm}$ long (Fig. $3 a)$. The surface layer of the base of the colony has radiates and derivatives of these (Fig. $3 b$, d), and unilaterally spinose spindles with long spines (Fig. $3 c)$. The interior of the base of the colony has spindles with sparse simple tubercles (Fig. 3e-f).

2) RMNH Coel. 32055, 6 colonies, Indonesia, SW Sulawesi, Spermonde Archipelago, W of Langkai Isl. (=37 km WNW of Ujungpandang), 502'S $119^{\circ} 05^{\prime} \mathrm{E}$, coral reef, scuba diving, 21 and 24.vi.1994, Buginesia Program UNHAS-NNM 1994, coll. B.W. Hoeksema; 'true' Nephthea.

The colony used is $10 \mathrm{~cm}$ long (Fig. 1b). The polyps are grouped at the end of the branches, forming conical catkins. Its sclerites are typical for a species of Nephthea. The polyps have a supporting bundle and eight irregular points (Fig. 2b). The supporting bundle spindles have their distal end unilaterally spinose (Fig. 4c). The spindles of the ventral points are rod-like (Fig. 4a, left), the dorsal points have unilaterally spinose spindles (Fig. 4a). The tentacles have flattened rods with a scalloped edge (Fig. 4b). Similarly shaped rods are also present at the ventral side of the polyp stalk (Fig. 2c). The surface layer of the base of the colony has radiates and derivatives of these (Fig. 4d), and unilaterally spinose spindles with long spines (Fig. 4e). The interior of the base 


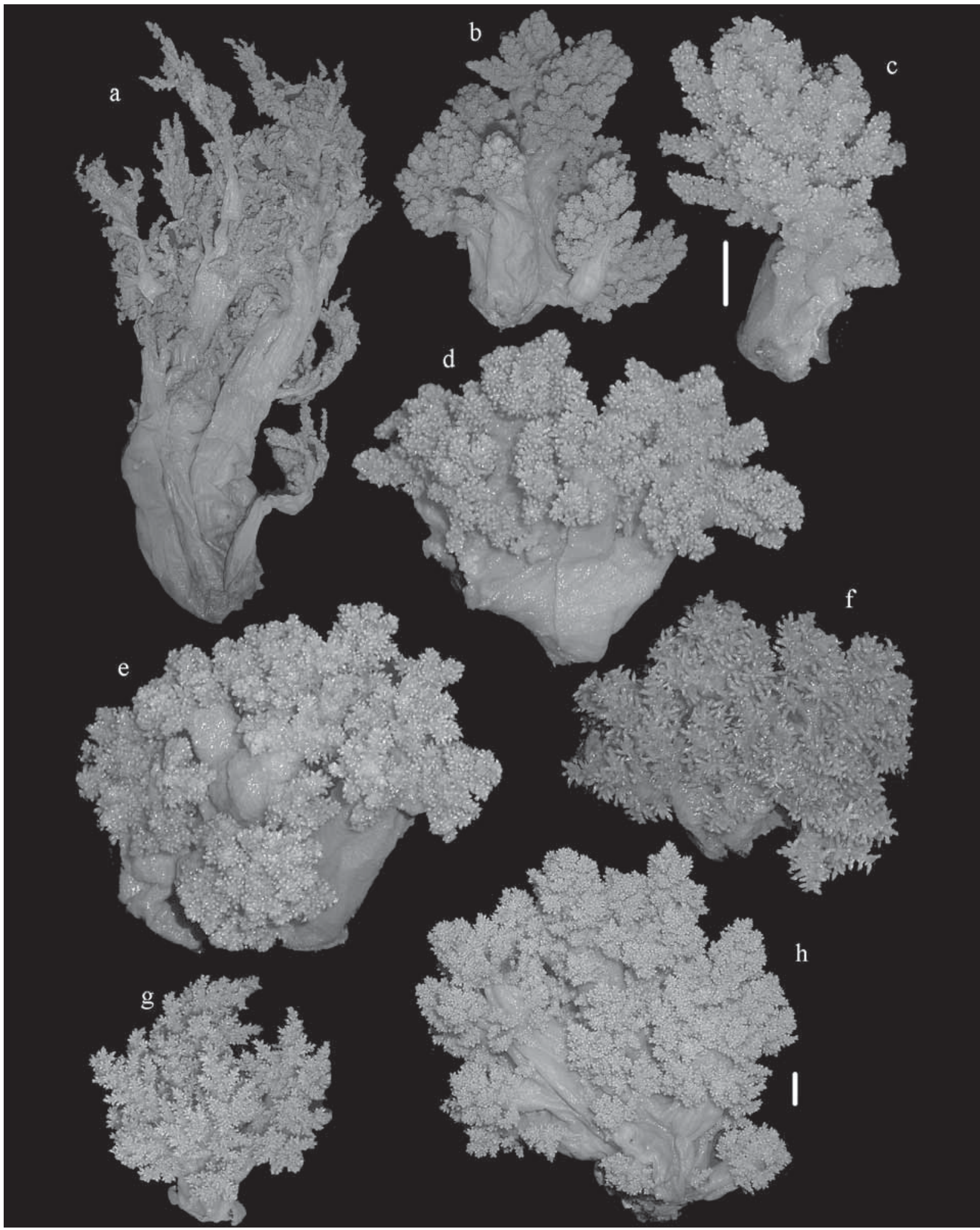

Fig. 1. Colonies; a, RMNH Coel. 32053; b, RMNH Coel. 32055; c, RMNH Coel. 34808; d, RMNH Coel. 34809; e, RMNH Coel. 34810; f, RMNH Coel. 34812; g, RMNH Coel. 34813; h, RMNH Coel. 34811. Scales $1 \mathrm{~cm}$, that at c also applies to f. 

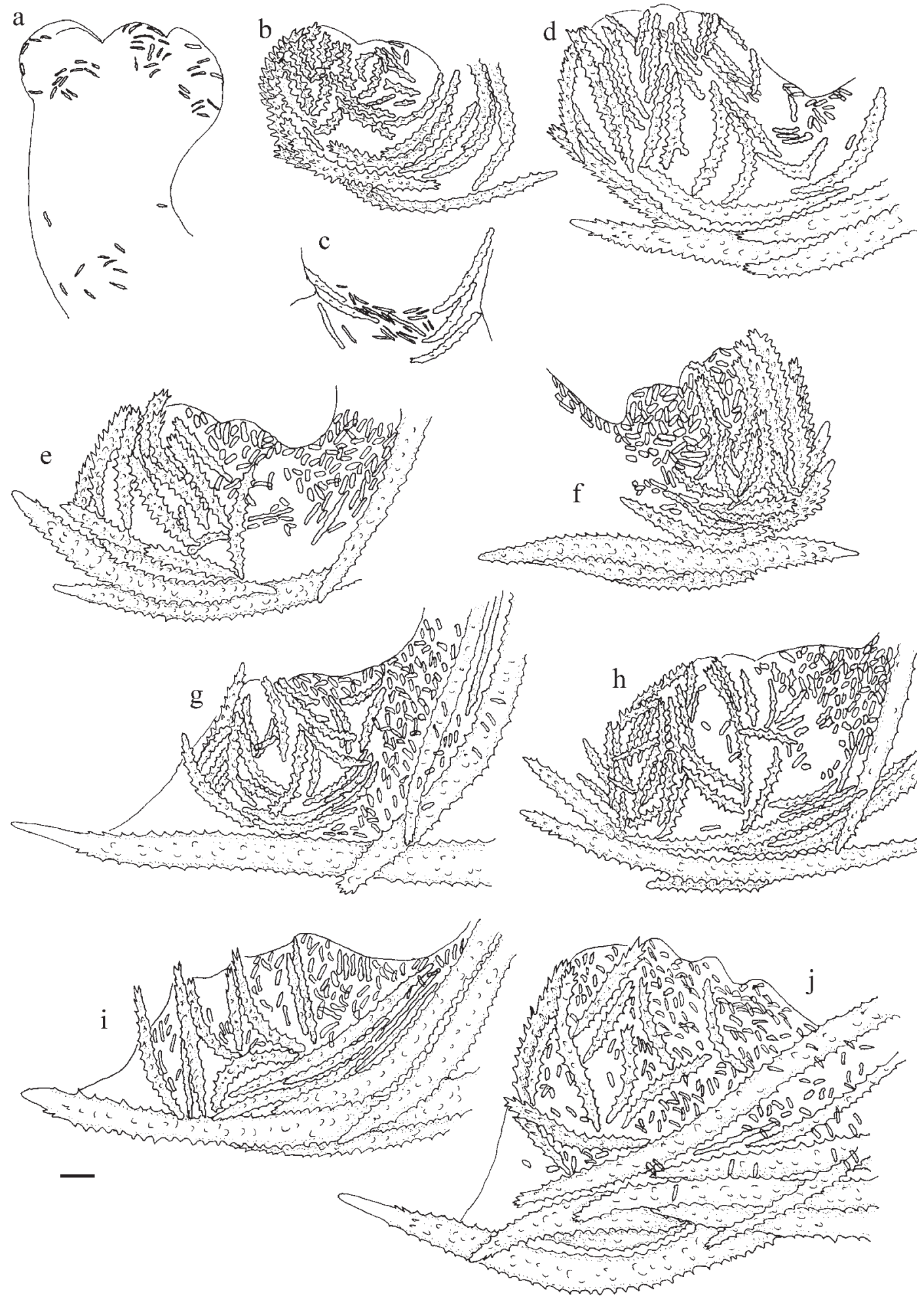

Fig. 2. Lateral views of polyps armature; a, RMNH Coel. 32053, b-c, RMNH Coel. 32055 (c, ventral side of polyp stalk); d, RMNH Coel. 34808; e-f, RMNH Coel. 34809; g, RMNH Coel. 34810; h, RMNH Coel. 34811; i, RMNH Coel. 34812; j, RMNH Coel. 34813. Scale $0.10 \mathrm{~mm}$. 


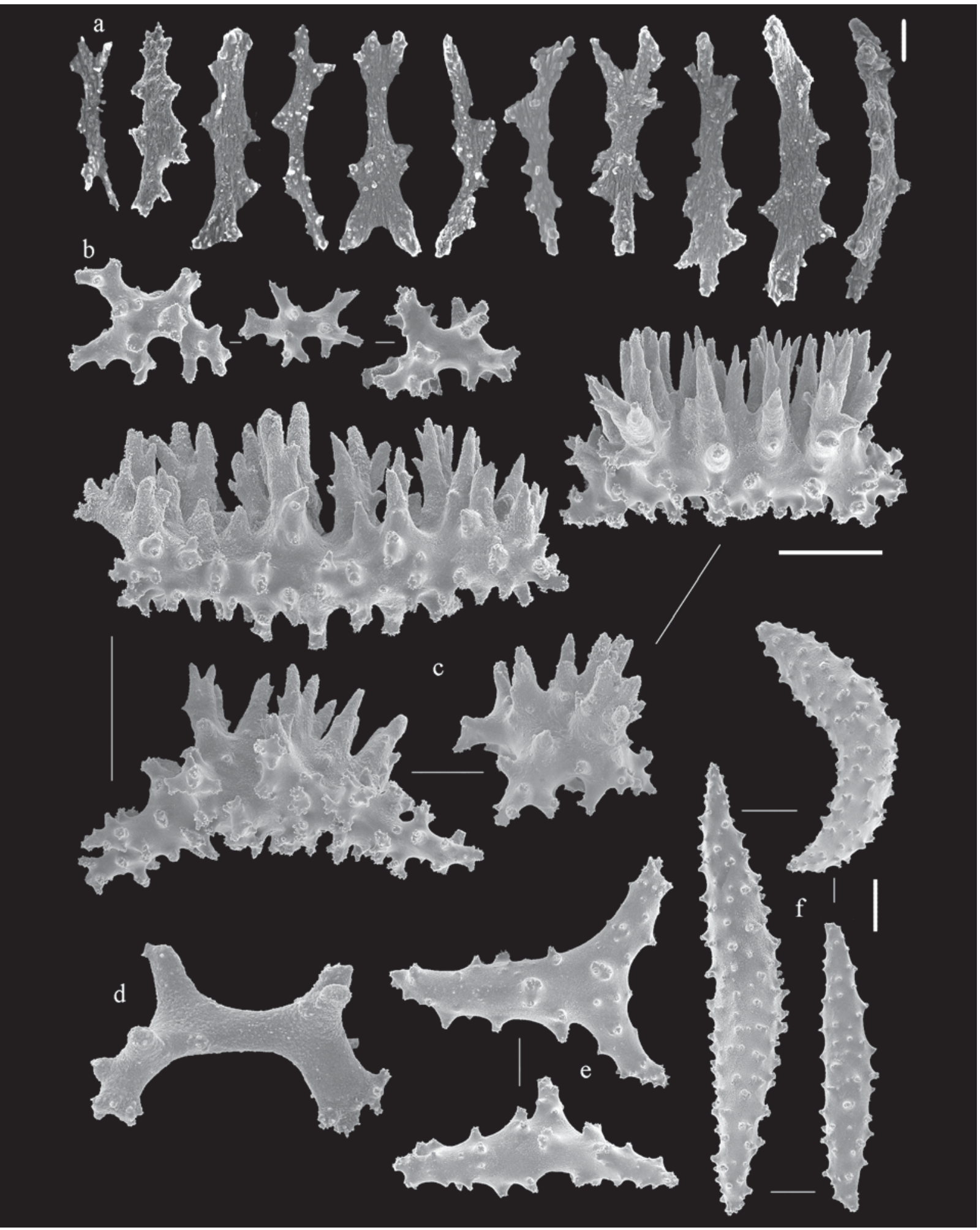

Fig. 3. RMNH Coel. 32053; a, rods of polyps; b, d, radiates, surface layer base of colony; c, unilaterally spinose spindles, surface layer base of colony; e-f, spindles, interior base of colony. Scale at a $0.01 \mathrm{~mm}$, also applies to d; scale at c $0.10 \mathrm{~mm}$, also applies to b, e; scale at $\mathrm{f} 0.10 \mathrm{~mm}$. 


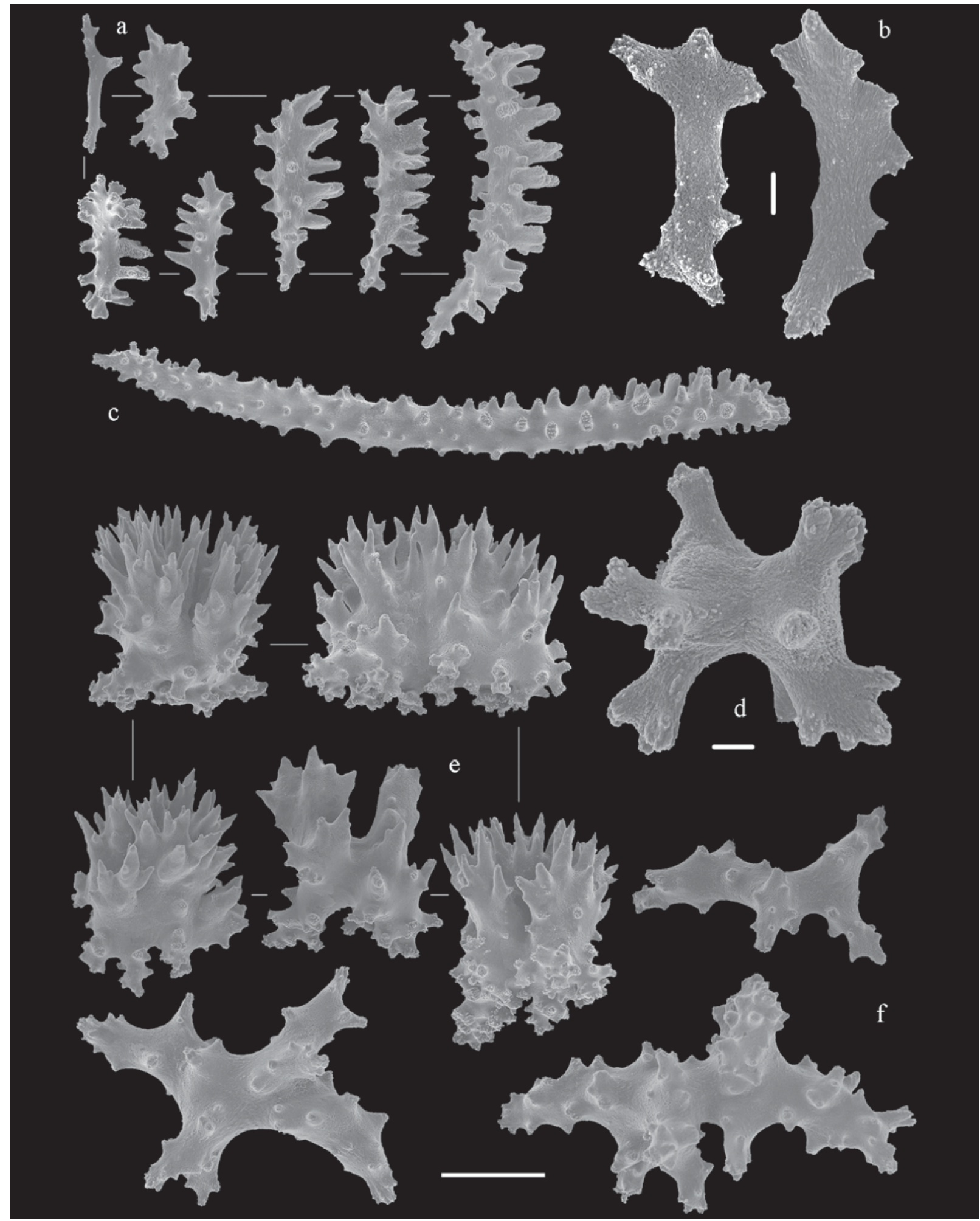

Fig. 4. RMNH Coel. 32055; a, rods and spindles of points, b, tentacular rods; c, spindle of supporting bundle; d, radiate, surface layer base of colony; e, unilaterally spinose spindles, surface layer base of colony; $\mathrm{f}$, branched spindles, interior base of colony. Scale at $\mathrm{b}$ and d $0.01 \mathrm{~mm}$, scale at f $0.10 \mathrm{~mm}$, also applies to a, c, e. 


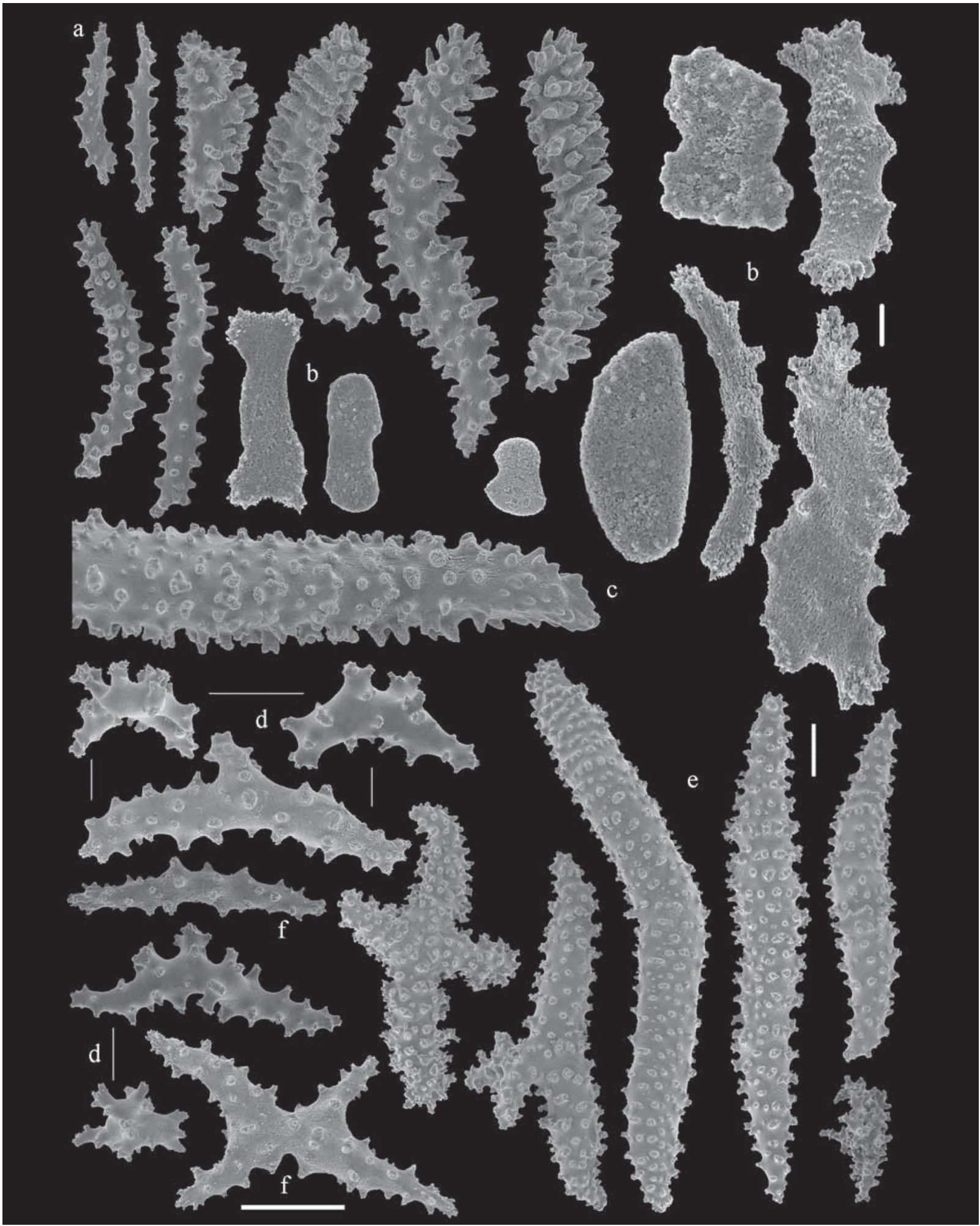

Fig. 5. RMNH Coel. 34808; a, point spindles, b, tentacular rods; c, spindle of supporting bundle (part); d-e, spindles, surface layer base of colony; f, spindles, interior base of colony. Scale at b $0.01 \mathrm{~mm}$, at $\mathrm{f}$ and e $0.10 \mathrm{~mm}$; that at $\mathrm{f}$ also applies to a, c, $\mathrm{d}$. 


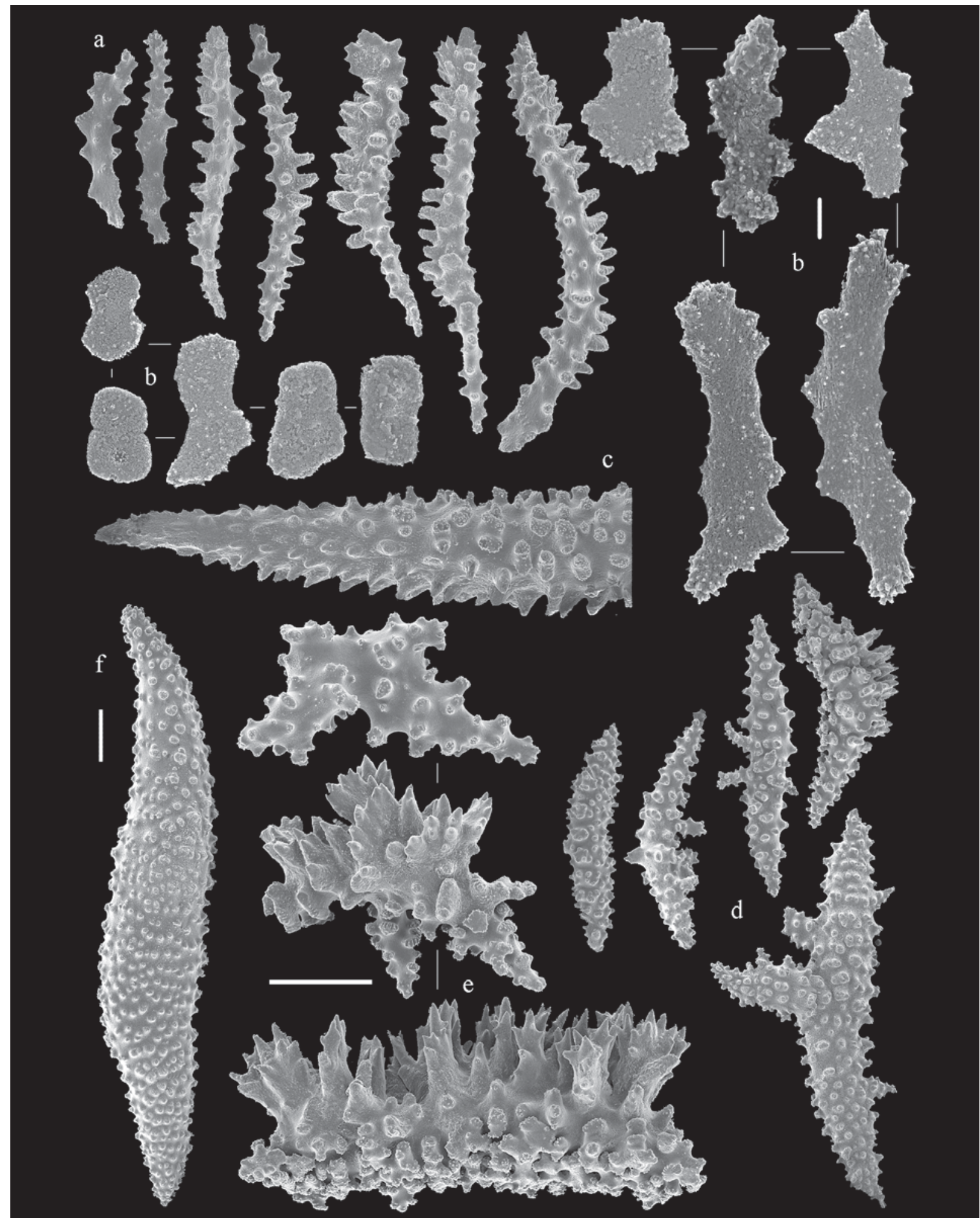

Fig. 6. RMNH Coel. 34809; a, point spindles, b, rods from tentacles, ventral points and polyp stalk; c, spindle of supporting bundle (part); d-e, spindles and unilaterally spinose spindles, surface layer base of colony; $\mathrm{f}$, spindle, interior base of colony. Scale at b 0.01 $\mathrm{mm}$, at $\mathrm{f}$ and e $0.10 \mathrm{~mm}$; that at $\mathrm{f}$ also applies to $\mathrm{d}$, that at e also to a, $\mathrm{c}$. 


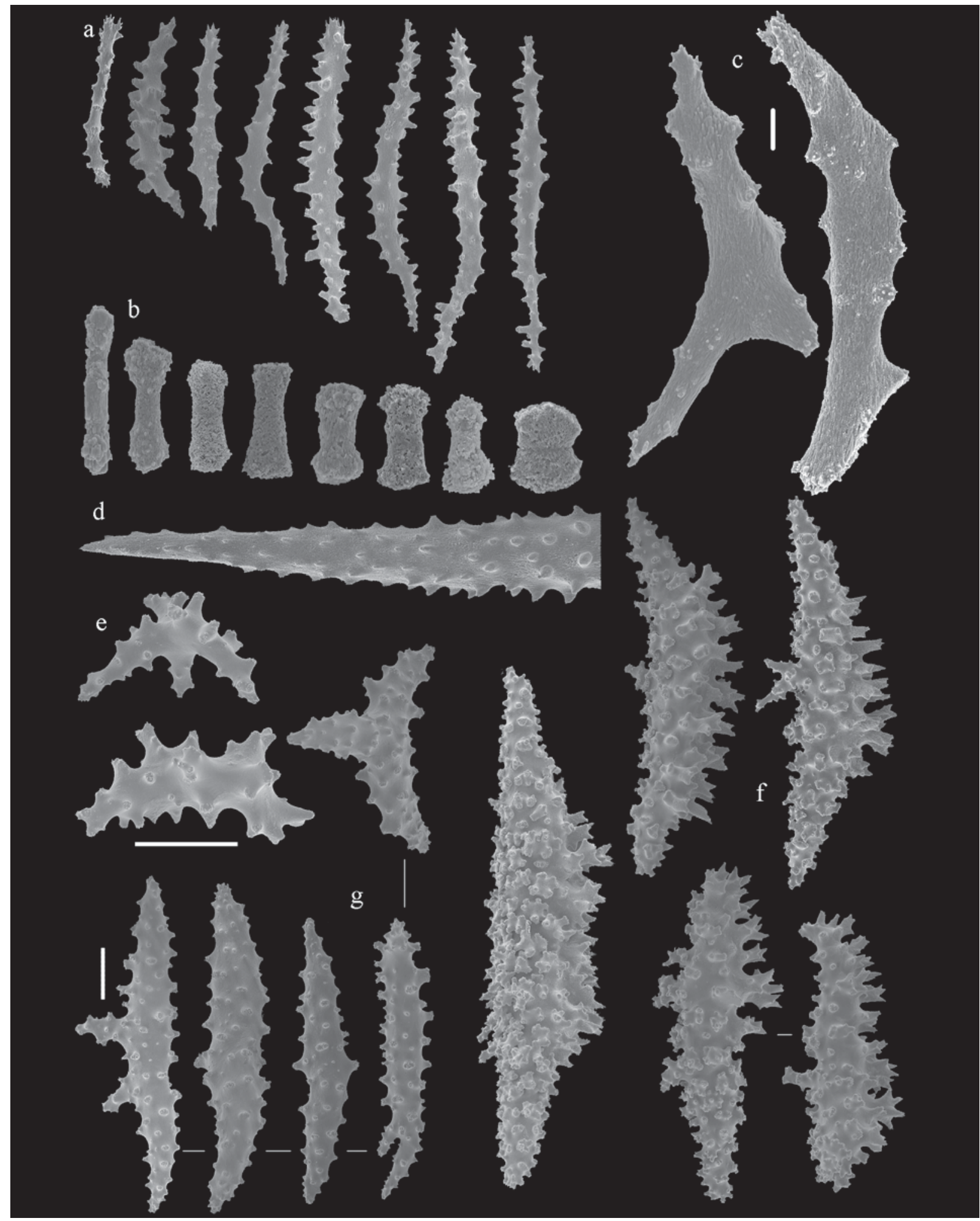

Fig. 7. RMNH Coel. 34810; a, point spindles, b, rods from ventral points and polyp stalk; c, tentacular rods; d, spindle of supporting bundle (part); e-f, spindles and unilaterally spinose spindles, surface layer base of colony; g, spindles, interior base of colony. Scale at c $0.01 \mathrm{~mm}$, also applies to $\mathrm{b}$; scales at e and $\mathrm{g} 0.10 \mathrm{~mm}$; that at e also applies to a, $\mathrm{d}$, that at $\mathrm{g}$ also to $\mathrm{f}$. 


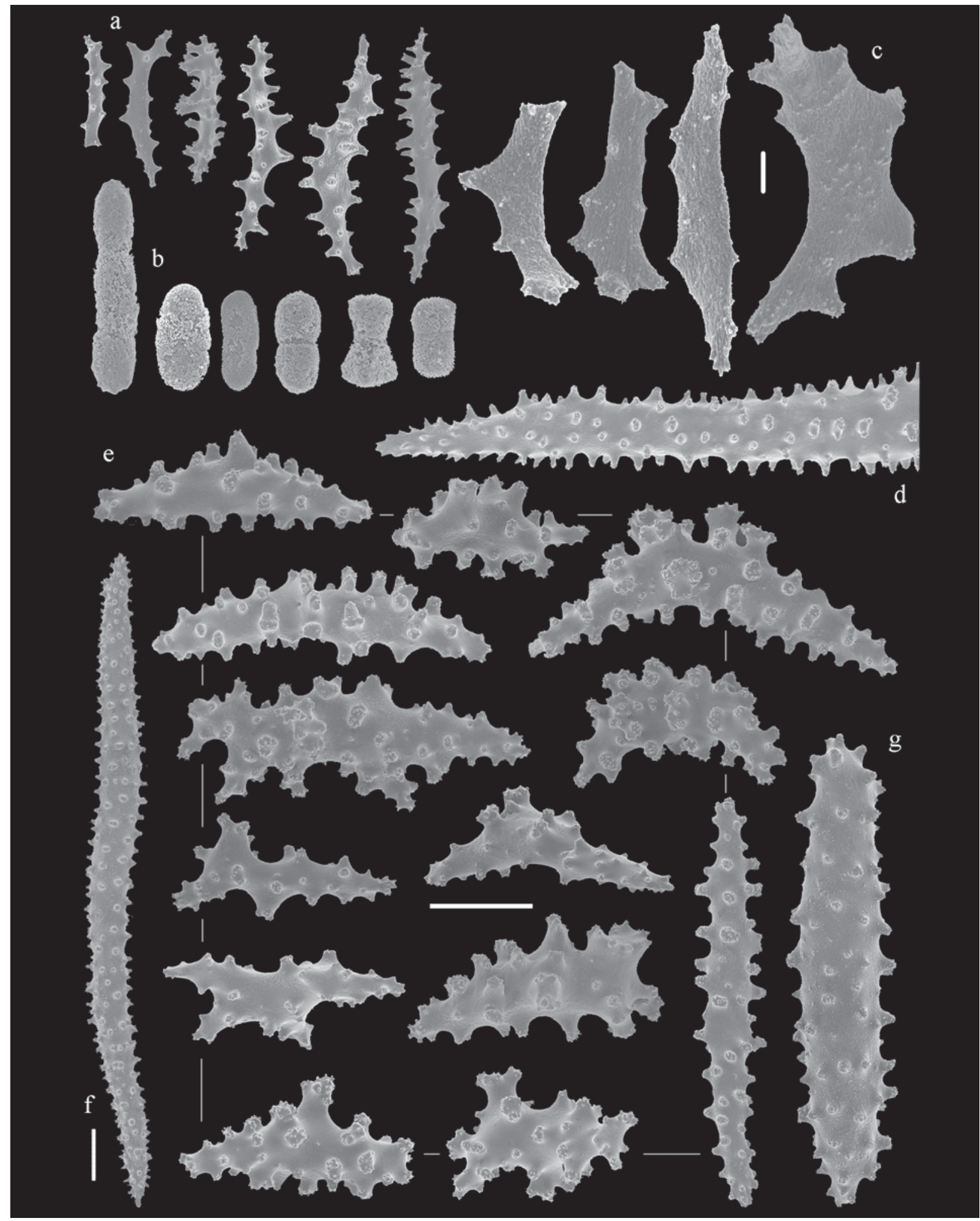

Fig. 8. RMNH Coel. 34811; a, point spindles, b, rods from ventral points and polyp stalk; c, tentacular rods; d, spindle of supporting bundle (part); e, spindles and unilaterally spinose spindles, surface layer base of colony; f-g, spindles, interior base of colony. Scale at c $0.01 \mathrm{~mm}$, also applies to $\mathrm{b}$; scales at e and $\mathrm{f} 0.10 \mathrm{~mm}$; that at e also applies to a, $\mathrm{d}, \mathrm{g}$. 


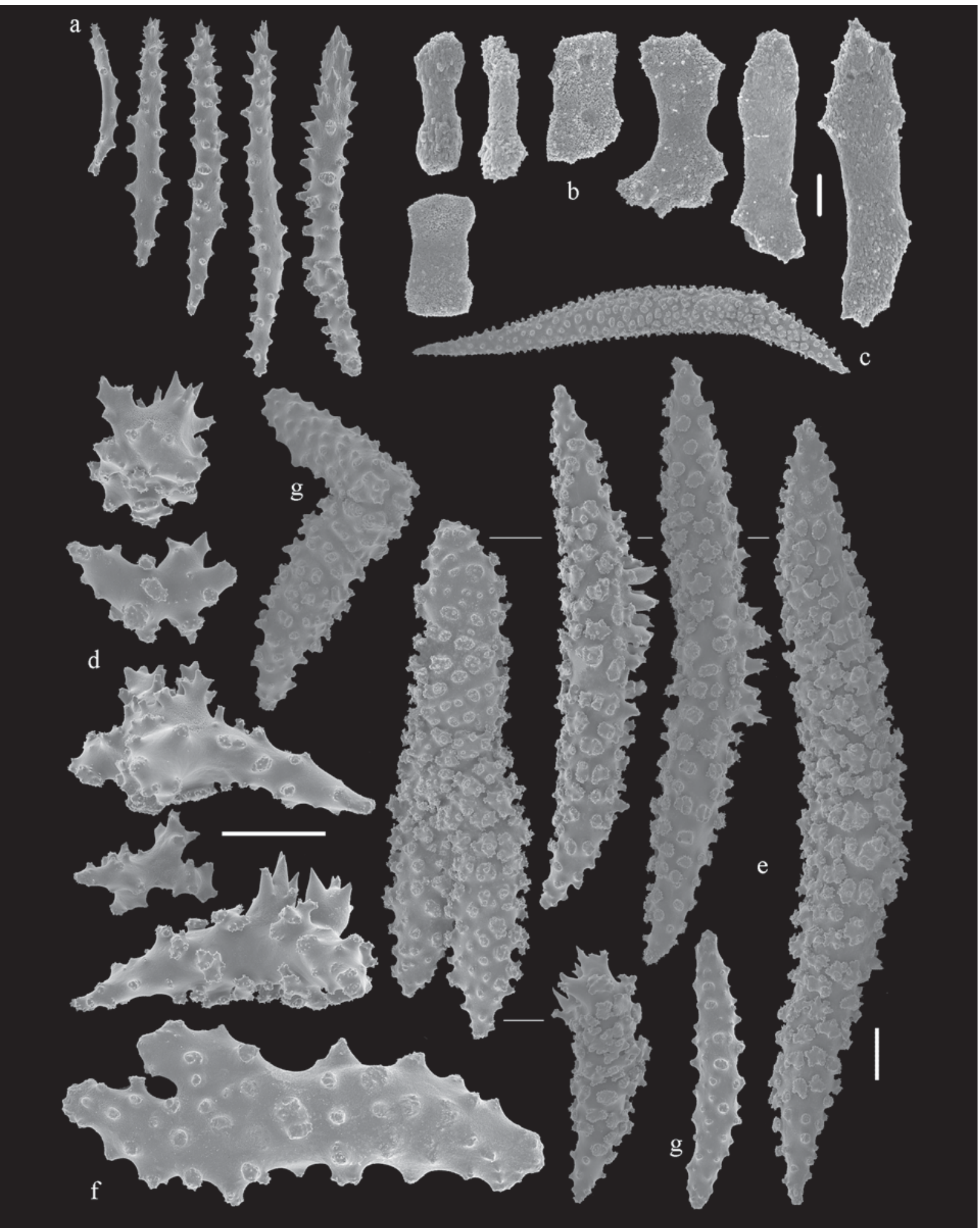

Fig. 9. RMNH Coel. 34812; a, point spindles, b, rods from tentacles, ventral points and polyp stalk; c, spindle of supporting bundle; d-e, spindles and unilaterally spinose spindles, surface layer base of colony; f-g, spindles, interior base of colony. Scale at b $0.01 \mathrm{~mm}$; scales at $\mathrm{d}$ and e $0.10 \mathrm{~mm}$; that at $\mathrm{d}$ also applies to $\mathrm{a}$, f; that at e also to $\mathrm{c}, \mathrm{g}$. 
of the colony has branched spindles with sparse simple tubercles (Fig. 4f).

3) RMNH Coel. 34808, KOR.09, Palau, "Toagel Mlungi Channel", channel in western barrier reef off Babeldaob, 07³2'33.0”N 134²8'06.6”'E; depth -25 m, coll. L.P. van Ofwegen,18.v.2005.

The colony is $6 \mathrm{~cm}$ long (Fig. 1c). The polyps are grouped at the end of the branches, forming irregularly shaped catkins. The polyps have eight points and a slightly projecting supporting bundle (Fig. 2d). The point spindles (Fig. 5a) and supporting bundle spindles (Fig. 5c) are bigger than in the previous RMNH Coel. 32055, but basically the same types occur. The species differs from the foregoing in having more rods on the ventral side of the polyp stalk, which hardly differ from those found in the tentacles (Fig. 5b). The surface layer of the base of the colony has spindles (Fig. 5e), and weakly developed unilaterally spinose spindles (Fig. 5d), many of them with side branches. The interior of the base of the colony has spindles with sparse simple tubercles, only a few smaller ones are depicted (Fig. 5f). They can be as long as $1.7 \mathrm{~mm}$, and are less tuberculate than the surface spindles.

4) RMNH Coel. 34809, BER.06, Indonesia, NE Kalimantan, Berau Islands, shoal between Lighthouse2 reef and Derawan Island; $02^{\circ} 12^{\prime} 08.6^{\prime \prime} \mathrm{N} 118^{\circ} 11^{\prime}$ 34.9'E, scuba diving, depth 20 m, coll. L.P. van Ofwegen and M. Slierings, 6.x.2003, E KalimantanBerau Exped.

The colony is $5 \mathrm{~cm}$ long (Fig. 1d). Like the previous two species the polyps are grouped at the end of the branches, forming irregularly shaped catkins. Also the polyp arrangement is much the same but differs in the ventral points and most of the polyp stalks having many rods (Figs. 2e-f, 6a-c). The surface layer of the base of the colony has spindles and unilaterally spinose spindles (Fig. 6d-e), many of them with side branches. The interior of the base of the colony has spindles with sparse simple tubercles (Fig. 6f), also many with side branches.

5) RMNH Coel. 34810, BER.26, Indonesia, NE Kalimantan, Berau Islands, Buliulin, NE-side (S of Samama Isl.); $02^{\circ} 07^{\prime} 07.2^{\prime \prime} \mathrm{N} 118^{\circ} 20^{\prime} 31.6 ” \mathrm{E}$, scuba diving, depth $-10 \mathrm{~m}$, coll. L.P. van Ofwegen and M. Slierings, 15.x.2003, E Kalimantan-Berau Exped. The colony is $6 \mathrm{~cm}$ long, with several stems arising from a common base (Fig. 1e). The catkin shape and polyp sclerite arrangement (Figs. 2g, 7b-d) is very much the same as in the previous species, however, the point sclerites are less unilaterally spinose (Fig. 7a). Also the base of the stalk has sclerites similar to those of RMNH Coel. 34809 (Fig. $7 \mathrm{e}-\mathrm{g})$, but these are also less unilaterally spinose.

6) RMNH Coel. 34811, BER.19a, Indonesia, NE Kalimantan, Berau Islands, off Tanjung Batu; 02 ${ }^{\circ} 4^{\prime}$ 47.6”N $118^{\circ} 05^{\prime} 36.6^{\prime \prime} \mathrm{E}$, scuba diving, depth $12 \mathrm{~m}$, coll. L.P. van Ofwegen and M. Slierings, 13.x.2003, E Kalimantan-Berau Exped.

The colony is $11 \mathrm{~cm}$ long, with several stems arising from a common base (Fig. 1h). The catkin shape and polyp sclerite arrangement (Fig. $2 \mathrm{~h}$ ) is very much the same as in the previous species. Also the polyp sclerites are similar (Fig. 8a-d). However, the sclerites of the surface layer of the base of the colony are only slightly unilaterally spinose (Fig. 8e), and hardly any sclerites of the base have side branches (Fig. 8f-g).

7) RMNH Coel. 34812, KOR.13, Palau, Koror, Uchelbeluu Reef, East side, barrier reef south-east of town of Koror, $07^{\circ} 16^{\prime} 25.2^{\prime \prime} \mathrm{N} 134^{\circ} 31^{\prime} 27.0^{\prime \prime} \mathrm{E}$; depth -30 m, coll. L.P. van Ofwegen, 20.v.2005.

The colony is $4 \mathrm{~cm}$ long (Fig. 1f). The polyps appear very spiny due to strong supporting bundles (Fig. 9c), and an arrangement in catkins is not recognizable. The polyp armature is also different from the above described species, with point spindles slightly protruding beyond the polyp head (Fig. 2i). These spindles are not unilaterally spinose but have a spiny distal end (Fig. 9a). Tiny rods (Fig. 9b) are not only present in the tentacles, ventral points and ventral side of the supporting bundle, but also in between the points. The surface layer of the base has spindles and unilaterally spinose spindles (Fig. 9d-e), some of which are very large (Fig. 9e). The interior has spindles with sparse tuberculation (Fig. 9f-g).

8) RMNH Coel. 34813, BER.31, Indonesia, NE Kalimantan, Berau Islands, Panjang Island, NE-side; $02^{\circ} 25^{\prime} 46.0^{\prime \prime} \mathrm{N} 118^{\circ} 09^{\prime} 49.1^{\prime \prime} \mathrm{E}$, scuba diving, depth $-25 \mathrm{~m}$, coll. L.P. van Ofwegen and M. Slierings, 19.x.2003, E Kalimantan-Berau Exped.

The colony is $8 \mathrm{~cm}$ long, but the base of the stalk is probably lost (Fig. 1g). Like in the previous species, the supporting bundles are strong (Fig. 10e), and catkins are not clearly discernable. In this species 
small rods (Fig. 10b-d) are present all over the polyps (Fig. $2 \mathrm{j}$ ), and the point spindles are unilaterally spinose (Fig. 10a). The surface layer of the base of the colony has spindles and unilaterally spinose spindles (Fig. 10f-g), the latter poorly developed. The interior has spindles with sparse tuberculation (Fig. 10h). The sclerites at the base of the colony look more like the types that are normally present higher up in the stalk of nephtheids. Hence we do not exclude the possibility that the lower part of the colony is lost.

9) RMNH Coel. 34814, KOR.15, Palau, Koror, Big Drop Off, east side of Ngemelis reef adjacent to island, $07^{\circ} 06^{\prime} 48.8^{\prime \prime} \mathrm{N} 134^{\circ} 15^{\prime} 36.4^{\prime \prime} \mathrm{E}$; depth $-25 \mathrm{~m}$, coll. L.P. van Ofwegen, 23.v.2005.

The colony is $6 \mathrm{~cm}$ long with a colony shape very much alike that of RMNH Coel. 34812, but with more slender lobes; catkins are not recognizable, and the stalk is covered by sponge tissue (Fig. 11c). Also the polyp armature (Figs. 12a, 13b-d) and shape of the point spindles (Fig. 13b) are similar to those of RMNH Coel. 34812. It differs by having the point sclerites protruding more beyond the polyp body, having less small rods in the polyp (Fig. 12a), and these rods being of a different shape (Fig. 13a). The surface layer of the base of the colony has radiates and derivatives of these, spindles and poorly developed unilaterally spinose spindles (Fig. $13 \mathrm{e})$. The interior of the base of the colony has spindles with sparse tuberculation (Fig. 13f).

10) RMNH Coel. 34815, KOR.03, Palau, Koror, Mutremdiu, west side Uchelbeluu Reef, barrier reef south-east of town of Koror, $07^{\circ} 16^{\prime} 25.2^{\prime \prime} \mathrm{N}$ $134^{\circ} 31$ '26.8' E; depth -25 m, coll. L.P. van Ofwegen, 13/21.v.2005.

The colony is $10 \mathrm{~cm}$ high, yellow with white polyps, and a real stalk is lacking (Fig. 11b). The colony shape is typical for a species of Stereonephthya with the polyps making an acute angle with their polyp stalk and supporting bundles projecting considerably beyond the polyps (Figs. 12b, 14d). The points have very big spindles, some of which also project beyond the polyp with the projecting part often widened and less spiny (Fig. 14b). The polyp stalk and tentacle rods (Fig. 14a, c) are similar to those of the previous species. The surface layer of the base of the colony has radiates, derivatives of these, spindles, and poorly developed unilaterally spinose spindles (Fig. 14e-f). The interior of the base of the colony has very few spindles, and these have sparse tuberculation (not depicted).

11) RMNH Coel. 34816, KOR.06, Palau, Koror, Wonder Channel (Rock Islands), NW side of Mercherchar Island, $07^{\circ} 10^{\prime} 56.5^{\prime \prime} \mathrm{N} 134^{\circ} 21^{\prime} 38.7^{\prime \prime} \mathrm{E}$; depth -25 m, coll. L.P. van Ofwegen, 16.v.2005.

Two colonies lacking a real stalk; red with white polyps. Sclerites of this material were similar to those of RMNH Coel. 34815.

12)RMNH Coel. 32058, PAL.06, Palau, E off Koror I. (Oreor I.), SW off Ngeream peninsula, patch reef in $\mathrm{KB}$ channel, $07^{\circ} 20^{\prime} 22.2^{\prime \prime} \mathrm{N} 134^{\circ} 31^{\prime} 04.6^{\prime \prime} \mathrm{E}$, 20.vii-6.viii.2002, coll. B.W. Hoeksema.

Several colonies, with sclerites and colony colour similar to RMNH Coel. 34815-16. For comparison the polyp armature is depicted (Fig. 12c).

13) RMNH Coel. 32059, 1 colony, Indonesia, SW Sulawesi, Spermonde Archipelago, S of Panikiang Isl.) (= $90 \mathrm{~km} \mathrm{NNE}$ of Ujungpandang, offshore NW of Sumpangbinangae) $4^{\circ} 22^{\prime} \mathrm{S} 119^{\circ} 35^{\prime} \mathrm{E}$, coral reef, scuba diving, 30.viii.1994, Buginesia Program UNHAS-NNM 1994, coll. B.W. Hoeksema. The colony is $9 \mathrm{~cm}$ long, white with orange polyps, with typical Stereonephthya colony shape (Fig. 11a). The polyp armature (Fig. 15a-d) is like the previous species but the point sclerites are much smaller (Fig. 15b) and they do not project beyond the polyp (Fig. 12d). The sclerites of the surface layer of the base of the colony are more slender than in the previous species (Fig. 15e-f). The interior of the base of the colony has spindles with sparse tuberculation (Fig. 15g).

14) RMNH Coel. 32050, holotype of Chromonephthea franseni Van Ofwegen, 2005, SUL.06, Indonesia, N Sulawesi, Selat Lembeh, Pulau Lembeh, Pantai Parigi, $01^{\circ} 28^{\prime} \mathrm{N} 125^{\circ} 14^{\prime} \mathrm{E}$, small fringing reef up to $20 \mathrm{~m}$ wide, gently sloping from beach to $10 \mathrm{~m}$, deeper slope sandy to muddy to $20 \mathrm{~m}$, diving and snorkelling, 15/26.x.1994.

The colony has been described in Van Ofwegen (2005), and here the holotype (Fig. 11d) and polyp armature (Fig. 12e) are shown for comparison. The genus differs from Nephthea and Litophyton by being azooxanthellate. It differs from Stereonephthya and Neospongodes by lacking rods in the polyp stalk, and from Dendronephthya by having the polyps standing single instead of in small bundles. 


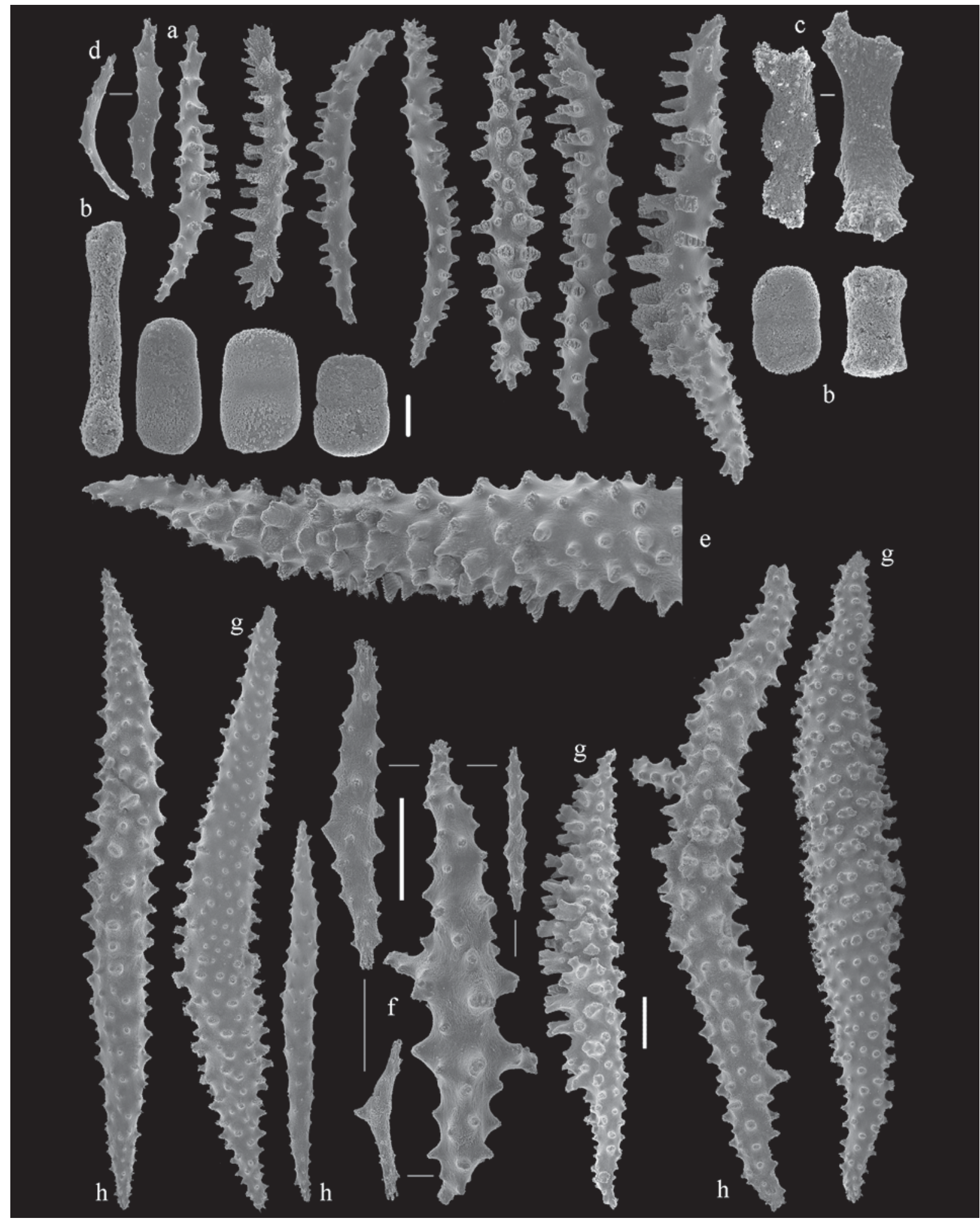

Fig. 10. RMNH Coel. 34813; a, point spindles; b, rods from polyp stalk; c-d, tentacular rods; e, spindle of supporting bundle (part); f-g, spindles and unilaterally spinose spindles, surface layer base of colony; h, spindles, interior base of colony. Scale at b $0.01 \mathrm{~mm}$, also applies to c; scales at $\mathrm{f}$ and $\mathrm{g} 0.10 \mathrm{~mm}$; that at $\mathrm{f}$ also applies to a, $\mathrm{d}$-e; that at $\mathrm{g}$ also to $\mathrm{h}$. 


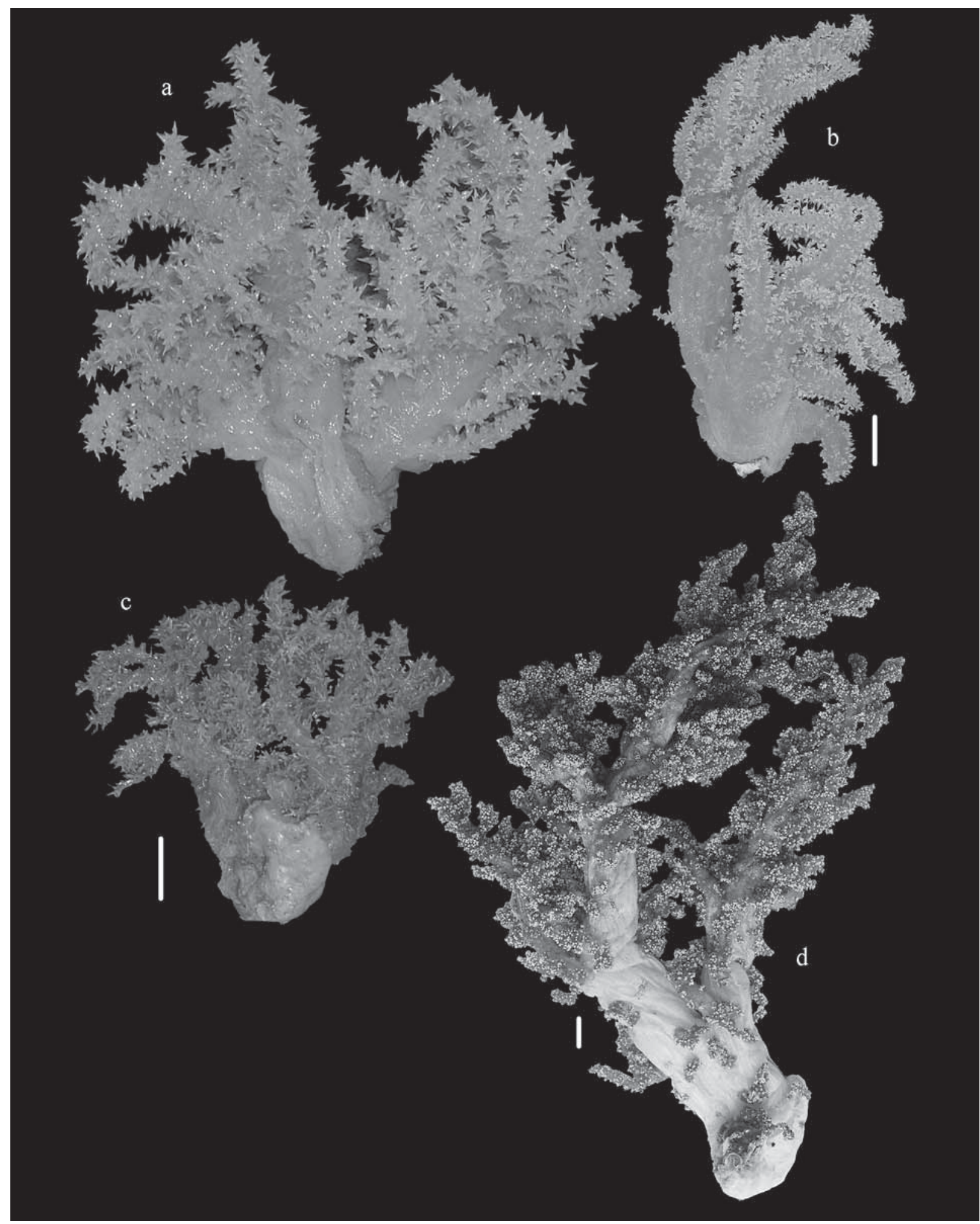

Fig. 11. Colonies; a, RMNH Coel. 32059; b, RMNH Coel. 34815; c, RMNH Coel. 34814; d, RMNH Coel. 32050, holotype of Chromonephthea franseni Van Ofwegen, 2005. Scales $1 \mathrm{~cm}$, that at b only applies to b, that at $\mathrm{d}$ only to $\mathrm{d}$. 


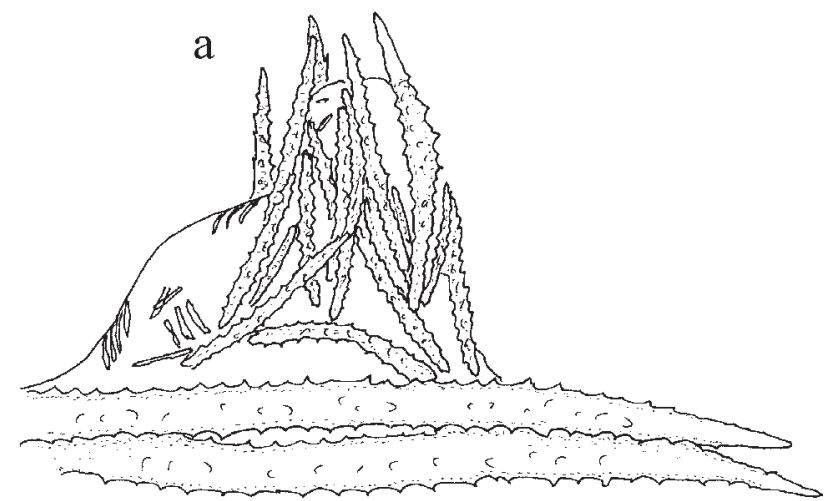

b

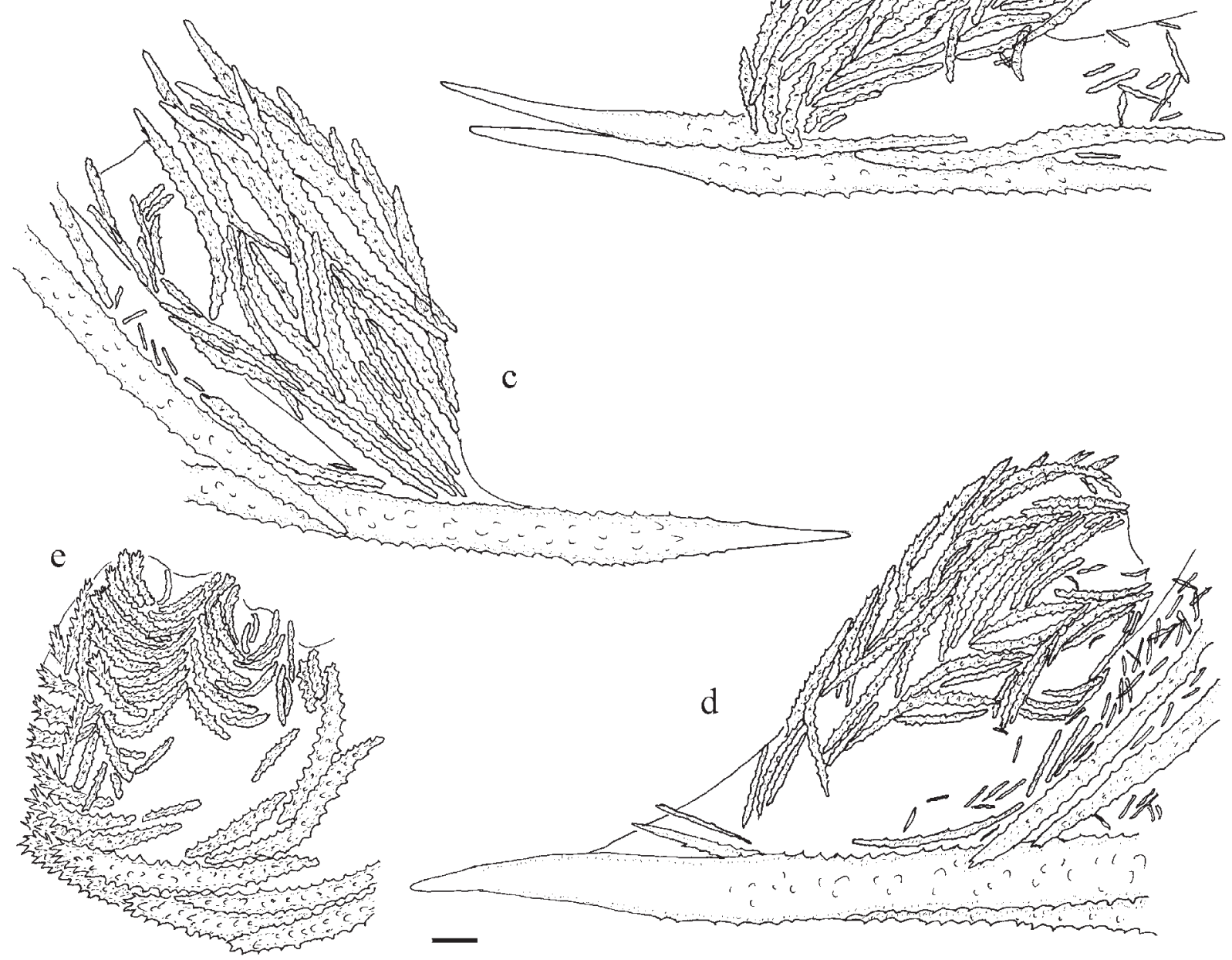

Fig. 12. Lateral views of polyps armature; a, RMNH Coel. 34814; b, RMNH Coel. 34815; c, RMNH Coel. 32058; d, RMNH Coel. 32059; e, RMNH Coel. 32050, holotype of Chromonephthea franseni Van Ofwegen, 2005. Scale $0.10 \mathrm{~mm}$. 


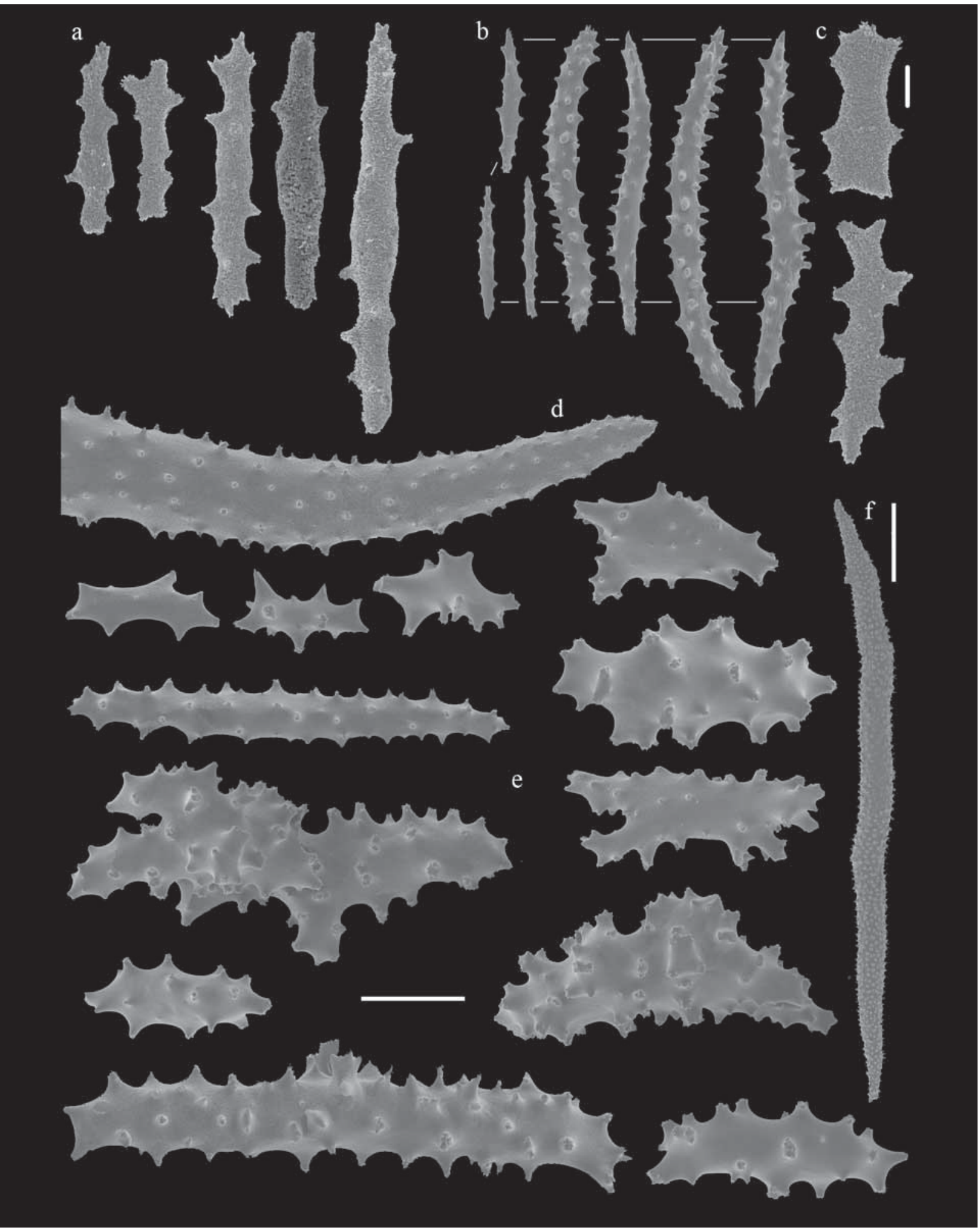

Fig. 13. RMNH Coel. 34814; a, rods of polyp stalk; b, point spindles; c, tentacular rods; d, spindle of supporting bundle (part); e, radiates, spindles and unilaterally spinose spindles, surface layer base of colony; f, spindle, interior base of colony. Scale at c $0.01 \mathrm{~mm}$, also applies to a; scales at e and $\mathrm{f} 0.10 \mathrm{~mm}$; that at e also applies to $\mathrm{b}, \mathrm{d}$. 


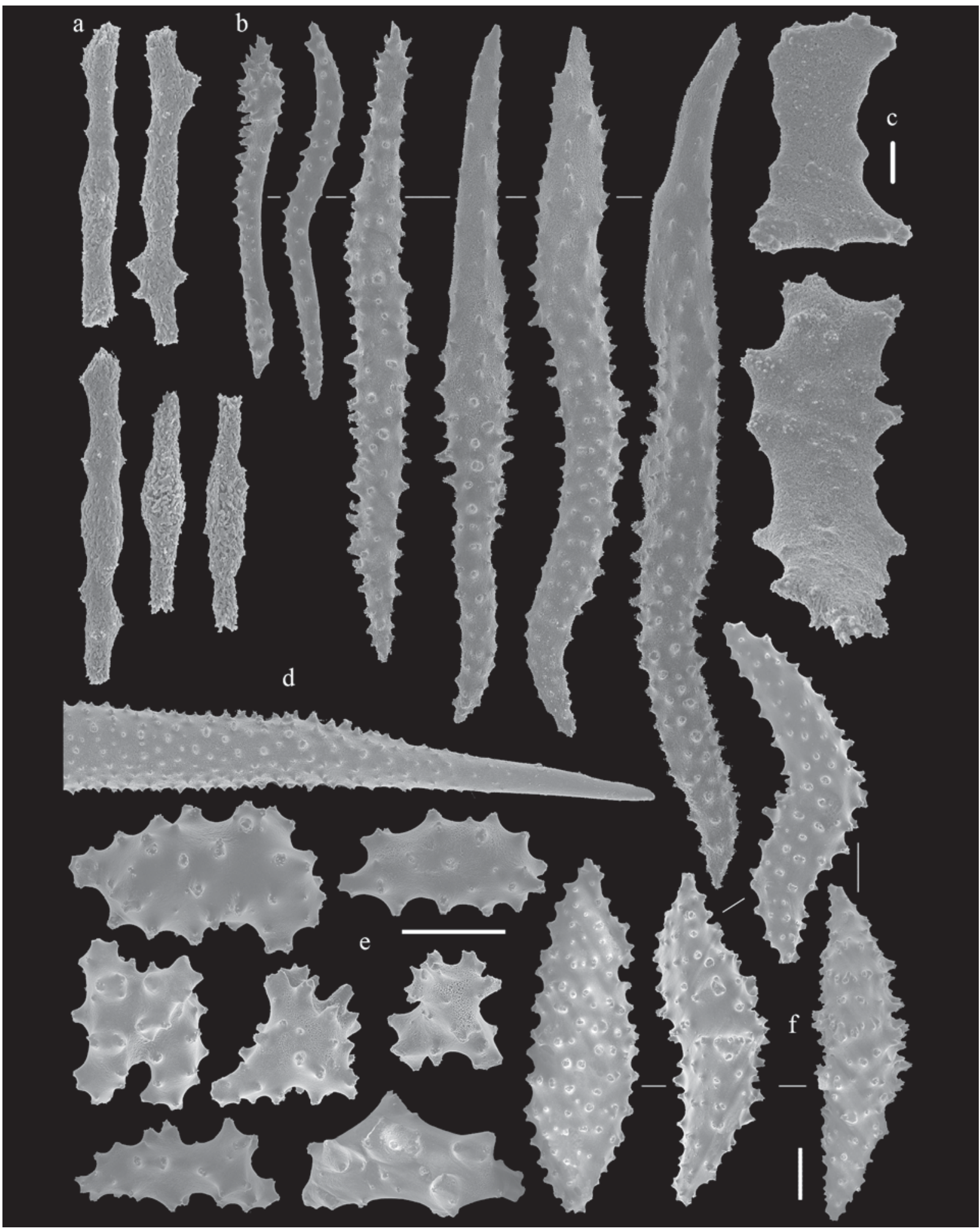

Fig. 14. RMNH Coel. 34815; a, rods of polyp stalk; b, point spindles; c, tentacular rods; d, spindle of supporting bundle (part); e-f, radiates, spindles and unilaterally spinose spindles, surface layer base of colony; Scale at c $0.01 \mathrm{~mm}$, also applies to a; scales at e and f 0.10 $\mathrm{mm}$; that at e also applies to $\mathrm{b}, \mathrm{d}$. 


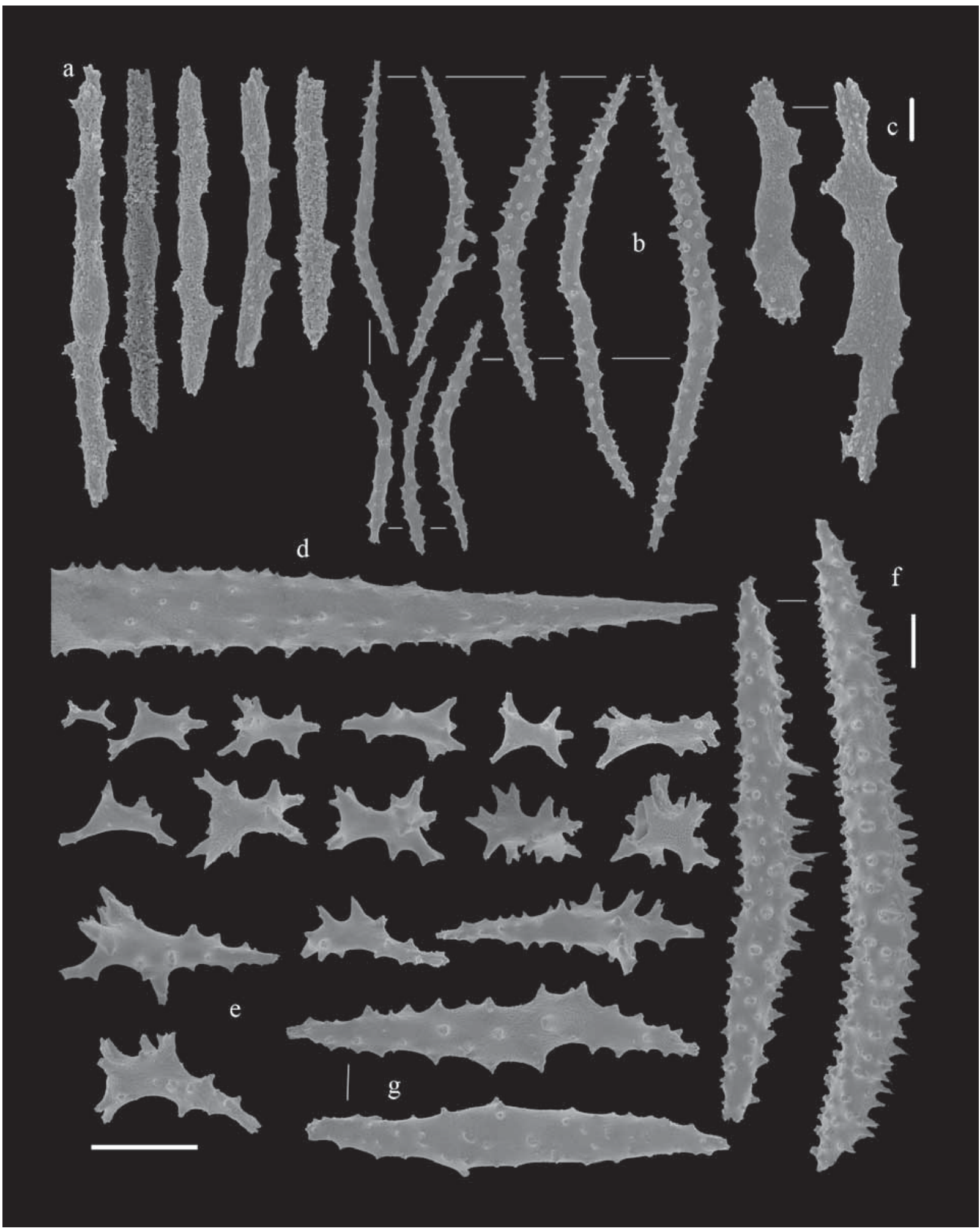

Fig. 15. RMNH Coel. 32059; a, rods of polyp stalk; b, point spindles; c, tentacular rods; d, spindle of supporting bundle (part); e-f, radiates, spindles and unilaterally spinose spindles, surface layer base of colony; g, spindles, interior layer base of colony. Scale at c 0.01 $\mathrm{mm}$, also applies to a; scales at e and $\mathrm{f} 0.10 \mathrm{~mm}$; that at e also applies to $\mathrm{b}, \mathrm{d}, \mathrm{g}$. 
In summary, the material used in the analyses includes one specimen referable to Litophyton (RMNH Coel. 32053), one to Nephthea (RMNH Coel. 32055), four to Stereonephthya (RMNH Coel. 34815-16; 32058-59), and one to Chromonephthea (RMNH Coel. 32050). All other specimens have intermediate characters and, according to the classification of Kükenthal, cannot be assigned to any genus or species unequivocally.

\section{Methods}

A small branch of each coral was preserved in $96 \%$ ethanol for molecular analysis. Around $0,25 \mathrm{~cm}^{3}$ of tissue was cut into small pieces for surface enlargement. Genomic DNA was extracted by use of a DNEasy ${ }^{\circledR}$ Tissue Kit (Qiagen) following the manufacturer's protocol for animal tissues. Elution volume was 50-100 $\mu \mathrm{l}$ and the average DNA concentration was around $1250 \mathrm{ng} / \mu \mathrm{l}$. Best PCR results were obtained using 1:10 dilutions and for most extracts, PCR's failed without the addition of Q-solution (Qiagen). Co-extraction of zooxanthellae was unavoidable and shown when we amplified the ITS-1 and ITS-2 regions.

Initial attempts to sequence mitochondrial marker MSH with primers ND42599F 5'-GCCATTATGGTTAACTATTAC-3' and Mut-3458R 5'-TSGAGCAAAAGCCACTCC-3' (France and Hoover, 2001, 2002) failed for most taxa. Therefore we designed internal primers MSH-Neph-F 5'-TATGAACTTTGGCATGAGCC-3' and MSH-Neph-R 5'-TGCCC AAATTACTATTTCTCTAATACG-3' specific for these nephtheids. PCR-reactions were done using a standard Taq DNA polymerase kit from Qiagen. Reaction volume always was $25 \mu \mathrm{l}$ and PCR conditions were 0.2 $\mathrm{mM}$ DNTPs, $0.4 \mu \mathrm{M}$ of each primer, $5 \mu \mathrm{l}$ of Q-solution, 5 units of Taq DNA polymerase (Qiagen) and no additional $\mathrm{MgCl}_{2}$ (PCR-buffer always contains 1.5 $\mathrm{mM} \mathrm{MgCl}{ }_{2}$ ). Thermocycling conditions were $3 \mathrm{~min}$. at $94^{\circ} \mathrm{C}$ for initial denaturation followed by 40 cycles $(15$ sec. at $94^{\circ} \mathrm{C}, 1 \mathrm{~min} .30 \mathrm{sec}$. at $50^{\circ} \mathrm{C}$ and $1 \mathrm{~min}$. at $72^{\circ} \mathrm{C}$ ) and final extension $5 \mathrm{~min}$. at $72^{\circ} \mathrm{C}$. PCR products were purified using Nucleospin ${ }^{\circledR}$ kit (Macherey-Nagel) and cycle sequenced in both directions with an ABI Dye Terminator Cycle Sequencing Kit (PE Biosystems). The sequenced products were purified using G-50 Fine Sephadex ${ }^{\circledR}$ columns and run on an ABI 377 automated sequencer. Sequences were checked and edited with Sequencer 4.2 (Genecodes inc.).

The resulting MSH sequences were hardly informative and did not give enough resolution to show rela- tionships below the genus-level. Hence another marker, the nuclear region 18S-ITS1-5.8S-ITS2-28S for which some information was also available on Genbank was tried. This region was amplified with primers 1w - F 5'-TACCGATTGAATGGTTTAGTGAGG-3' (McFadden and Hutchinson, 2004) and 2w 5'-ATTGCCACGTACGGGGTTGTC-3' (McFadden et al., 2001). PCR conditions, as well as product purification (for both PCR and sequenced products) were identical to the procedure described above. Thermocycling conditions were $3 \mathrm{~min}$. at $94^{\circ} \mathrm{C}$ for initial denaturation followed by 40 cycles $\left(15 \mathrm{sec}\right.$. at $94^{\circ} \mathrm{C}, 1 \mathrm{~min} .30 \mathrm{sec}$. at $52^{\circ} \mathrm{C}$ and $1 \mathrm{~min} .30 \mathrm{sec}$. at $72^{\circ} \mathrm{C}$ ) and final extension 5 min. at $72^{\circ} \mathrm{C}$. Next to primer $1 \mathrm{w}-\mathrm{F}$ and $2 \mathrm{w}$, internal primers LVO 5.8s Fwd1 5'-TTAACGGTGGATCT CTTGGCTC-3' and LVO 5.8s Rev 2 5'-TCACACTACTTATCGCAGCTGG-3'were used for cycle sequencing. This generated 4 overlapping sequences that were also assembled with Sequencer 4.2 (Genecodes inc.).

\section{Sequence variation}

The sequences we used ranged from $860 \mathrm{bp}(\mathrm{RMNH}$ Coel. 34814) to $977 \mathrm{bp}$ (RMNH Coel. 32053) in length. All sequences included the $157 \mathrm{bp}$ of the $5.8 \mathrm{~S}$ gene, the 3 ' terminus of $18 \mathrm{~S}$ ranged from $114 \mathrm{bp}$ (most sequences) to 117 bp (RMNH Coel. 32050), but was mostly $114 \mathrm{bp}$ long. The 5 ' end of $28 \mathrm{~S}$ was

Table 1. Variation in length and base composition of ribosomal internal transcribed spacer regions (ITS-1, ITS-2) among species of nephtheids. Alcyonium digitatum is included as outgroup. $\mathrm{bp}=$ base pairs, $\mathrm{CG}=$ cytosine and guanine.

\begin{tabular}{lllll}
\hline & ITS1 & \multicolumn{3}{l}{ ITS2 } \\
\cline { 2 - 5 } & Length bp & \%CG & Length bp & \%CG \\
\hline 1550 & 230 & 45.22 & 192 & 60.42 \\
\hline 2028 & 230 & 45.22 & 192 & 60.42 \\
\hline 2031 & 230 & 45.22 & 192 & 60.42 \\
\hline 1551 & 217 & 44.24 & 181 & 59.67 \\
\hline 2036 & 219 & 44.29 & 174 & 59.20 \\
\hline 1542 & 220 & 45.46 & 208 & 60.10 \\
\hline 1858 & 207 & 42.03 & 216 & 64.81 \\
\hline 1547 & 208 & 41.83 & 202 & 63.86 \\
\hline 2033 & 223 & 42.16 & 207 & 59.90 \\
\hline 1861 & 223 & 44.40 & 212 & 68.87 \\
\hline 1860 & 225 & 44.00 & 218 & 69.72 \\
\hline 1859 & 207 & 44.93 & 203 & 66.99 \\
\hline 2035 & 225 & 48.44 & 203 & 69.45 \\
\hline 1545 & 251 & 43.03 & 260 & 61.92 \\
\hline A digi & 185 & 40.00 & 197 & 52.79 \\
\hline & & & &
\end{tabular}


Table 2. Genetic distances among nephtheid species (Kimura two-parameter method). Distances are given for combined 18S, ITS-1, 5.8S, ITS-2, and 28S. Stereonephthya data in bold.

\begin{tabular}{|c|c|c|c|c|c|c|c|c|c|c|c|c|c|c|c|}
\hline & 32058 & 34815 & 34816 & 32059 & 34814 & 32051 & 34813 & 34810 & 34811 & 34812 & 32053 & 34809 & 32055 & 34808 & Adig \\
\hline 32058 & - & & & & & & & & & & & & & & \\
\hline 34815 & 0.00000 & & & & & & & & & & & & & & \\
\hline 34816 & 0.00227 & 0.00227 & - & & & & & & & & & & & & \\
\hline 32059 & 0.00587 & 0.00587 & 0.00709 & - & & & & & & & & & & & \\
\hline 34814 & 0.00591 & 0.00591 & 0.00829 & 0.00938 & - & & & & & & & & & & \\
\hline 32051 & 0.07664 & 0.07664 & 0.07795 & 0.07808 & 0.07386 & - & & & & & & & & & \\
\hline 34813 & 0.10277 & 0.10277 & 0.10420 & 0.09619 & 0.09059 & 0.08439 & - & & & & & & & & \\
\hline 34810 & 0.10299 & 0.10299 & 0.10442 & 0.09532 & 0.08983 & 0.08359 & 0.01349 & - & & & & & & & \\
\hline 34811 & 0.09430 & 0.09430 & 0.09572 & 0.08922 & 0.08656 & 0.08477 & 0.02020 & 0.02475 & - & & & & & & \\
\hline 34812 & 0.09560 & 0.09560 & 0.09696 & 0.08626 & 0.08348 & 0.07934 & 0.03797 & 0.03906 & 0.03557 & - & & & & & \\
\hline 32053 & 0.10068 & 0.10068 & 0.10214 & 0.09463 & 0.08900 & 0.09003 & 0.03947 & 0.04464 & 0.04739 & 0.04260 & - & & & & \\
\hline 34809 & 0.08804 & 0.08804 & 0.08950 & 0.08472 & 0.08047 & 0.07881 & 0.04751 & 0.05058 & 0.04502 & 0.04939 & 0.04783 & - & & & \\
\hline 32055 & 0.08079 & 0.08079 & 0.08224 & 0.08341 & 0.07535 & 0.07382 & 0.05065 & 0.05374 & 0.05127 & 0.04609 & 0.04533 & 0.02233 & - & & \\
\hline 34808 & 0.09781 & 0.09781 & 0.09804 & 0.09555 & 0.08760 & 0.09056 & 0.05973 & 0.06273 & 0.06368 & 0.06775 & 0.06908 & 0.02938 & 0.03061 & - & \\
\hline Adig & 0.12314 & 0.12314 & 0.12473 & 0.11782 & 0.11381 & 0.12163 & 0.11517 & 0.11562 & 0.10803 & 0.11560 & 0.12185 & 0.11234 & 0.11314 & 0.11556 & - \\
\hline
\end{tabular}

194 bp long in all sequences. Both of the ITS regions varied greatly in length among species, ITS-1 ranged from 207 bp (RMNH Coel. 34809; RMNH Coel. 34811 ) to $251 \mathrm{bp}$ (RMNH Coel. 32053), and ITS-2 ranged from $174 \mathrm{bp}$ (RMNH Coel. 34814) to $260 \mathrm{bp}$ (RMNH Coel. 32053) (Table 1). As the outgroup Alcyonium digitatum (GenBank accession number AF2623461) was used.

The long sequence length of RMNH Coel. 32053 with $977 \mathrm{bp}$ is caused by its long ITS regions. In the ITS-2 region at position 547 there is a five times repeat of "GGCCCTTT", and at position 704 a three times repeat of "TAAAGCTCTT", which mostly explains for the extraordinary length. In the ITS-1 region such obvious repeats were not recognized.

RMNH Coel. 32058-59 and RMNH Coel. 34814-16 seem to have a shorter ITS2 region (on average 186.20) than the other nephtheids (on average 214.33).

The $\mathrm{G}+\mathrm{C}$ content of ITS 1 and ITS2 was calculated in GeneDoc (Table 1), the values for ITS-1 are comparable with those given for Alcyonium species by McFadden et al. (2001), the values for the ITS-2 region are on average more than $10 \%$ higher. No pattern could be recognized within the nephtheids.

Nucleotide diversity was estimated in PAUP using the Kimura two-parameter method (Table 2). Genetic distances of the combined partial sequence of the 5 , end of 18S rRNA gene, the complete sequence of ITS$1,5.8 \mathrm{~S}$ rRNA gene and ITS-2, and a partial sequence 3 ' end of 28S rRNA are presented in Table 2. The distance between RMNH Coel. 32058 and RMNH Coel. 34815 is $0 \%$ and that between these two and RMNH
Coel. 34814, 16 and RMNH Coel. 32059 is also very small, 0.0023-0.0094.

Sequences were aligned using ClustalW (Thompson et al. 1994) with parameter GOP (Gap Opening Penalty) set to 2 and the GEP (Gap Extension Penalty) to 1. Both McFadden et al. (2001) and Forsman et al. (2006) proved that this is the best alignment setting for Alcyonium (soft corals) and Porites/Siderastrea (stony corals).

Genbank accession numbers are presented in Table 3.

\section{Phylogenetic analyses}

We used the permutation test in PAUP (version 4.0b10; Swofford, 2002) for a phylogenetic signal, the $P$ value was 0.01 .

Table 3. GenBank accession numbers.

\begin{tabular}{ll}
\hline RMNH Coel. 32050_1542 & EF215838 \\
RMNH Coel. 32053_1545 & EF215839 \\
RMNH Coel. 32055_1547 & EF215840 \\
RMNH Coel. 32058_1550 & EF215841 \\
RMNH Coel. 32059_1551 & EF215842 \\
RMNH Coel. 34809_1858 & EF215843 \\
RMNH Coel. 34811_1859 & EF215844 \\
RMNH Coel. 34810_1860 & EF215845 \\
RMNH Coel. 34813_1861 & EF215846 \\
RMNH Coel. 34815_2028 & EF215847 \\
RMNH Coel. 34816_2031 & EF215848 \\
RMNH Coel. 34808_2033 & EF215849 \\
RMNH Coel. 34812_2035 & EF215850 \\
RMNH Coel. 34814_2036 & EF215851 \\
\hline
\end{tabular}


The final alignment included 1029 nucleotide positions: 685 are constant, 123 are variable, and 221 are parsimony-informative.

PAUP was used for maximum parsimony, neighbour-joining, and the Unweighted Pair Group Method with Arithmetic mean (UPGMA). For maximum parsimony we did bootstrap analyses (100 and 1000 replicates) using the heuristic-search option with simple addition of sequences and Tree-bisection-reconnection (TBR) branch swapping. The steepest descent option was in effect. Branches having maximum length zero were collapsed to yield polytomies. Multrees' option was in effect.

For neighbour-joining we used bootstrap analyses (1000 replicates) with consensus tree option set to 50\% majority-rule, for the rest we used default settings.

With MacClade (version 4.08) we examined the base pair positions used in the neighbour-joining tree analysis. As can be seen in Fig. 16 this mostly concerned positions in the poorly aligned ITS regions. Therefore, we also did the above analyses after removing the less aligned parts of the ITS regions.

Alcyonium digitatum was used to root all trees.

\section{Results}

The different number of replicates used in the bootstrap analysis of maximum parsimony resulted in only marginal differences.

The different methods yielded similar results. In all trees two clades are supported. In all but the partial ITS parsimony analysis clade I is formed by Chromonephthea franseni together with RMNH Coel. 32058-59 and RMNH Coel. 34814-16 and clade II includes all other specimens. Only in the partial ITS parsimony anal-

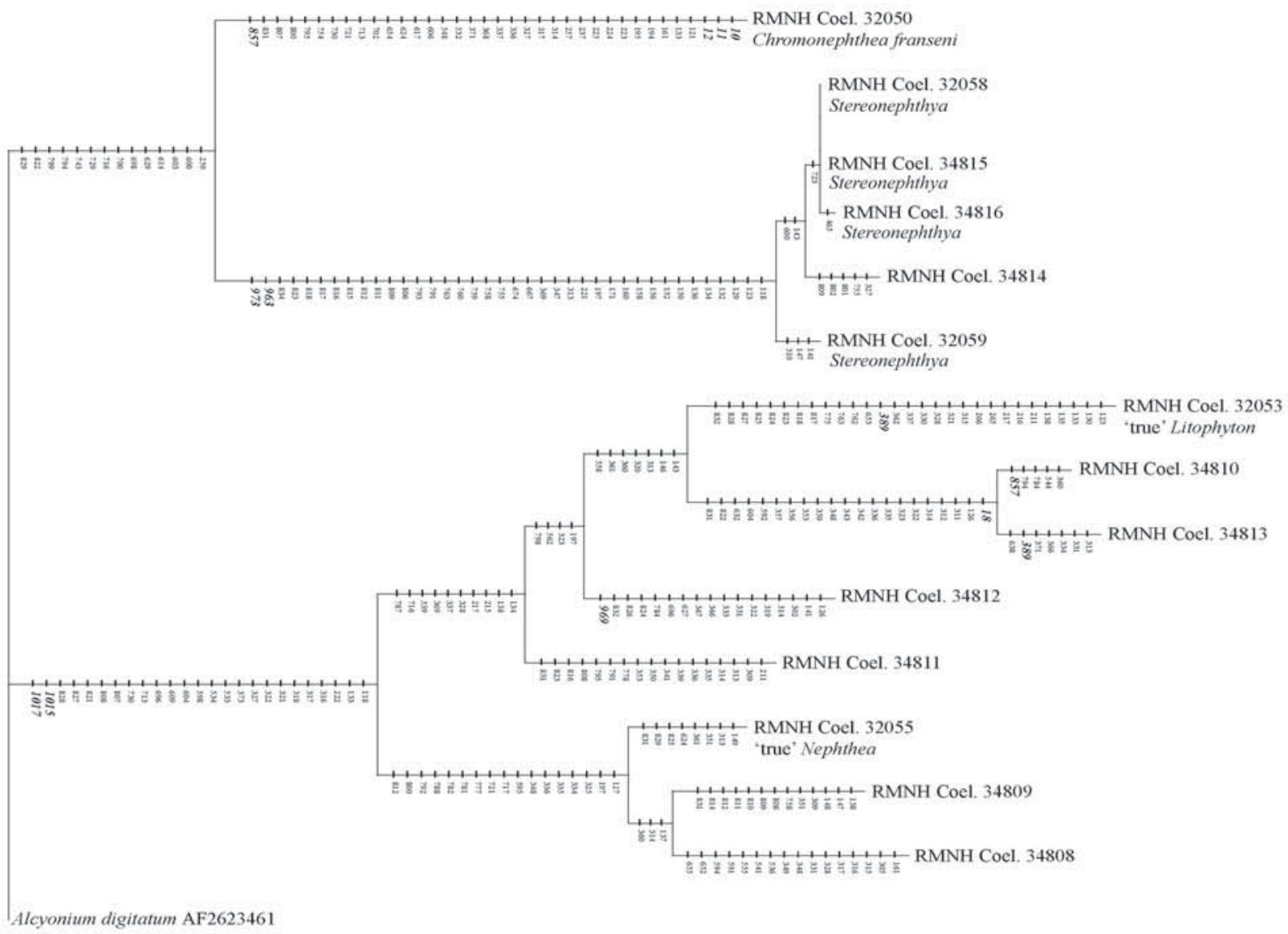

Fig. 16. Neighbour-joining bootstrap 50\% majority-rule consensus tree with base pair positions used in the analysis. Positions in the $18 \mathrm{~S}$, $5.8 \mathrm{~S}$, and $28 \mathrm{~S}$ regions are shown in bold and italics. 


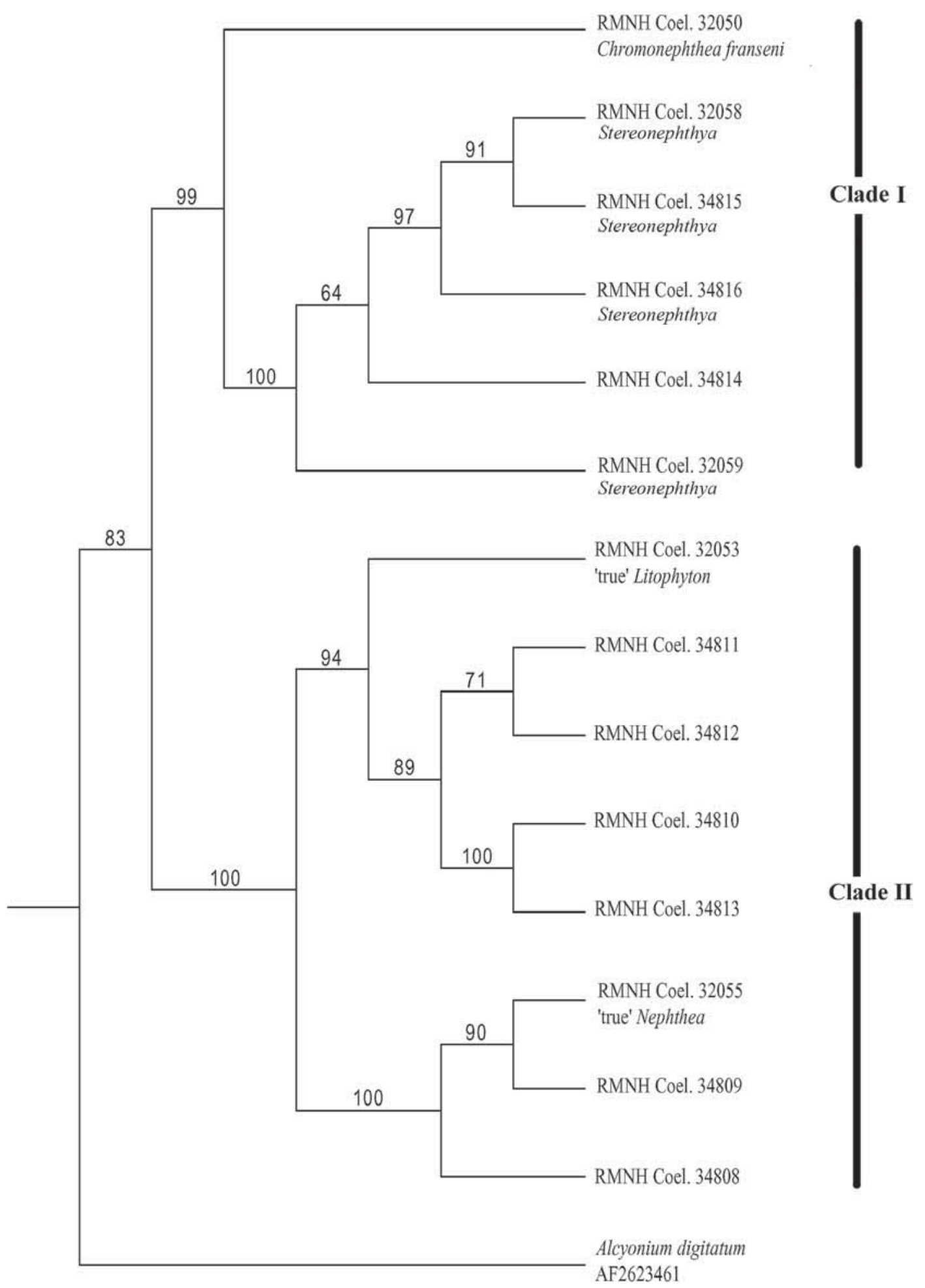

Fig. 17. Unweighted Pair Group Method with Arithmetic mean (UPGMA) bootstrap tree. 
ysis Chromonephthea franseni clustered in clade II.

Here we only present the results of the UPGMA analysis (Fig. 17). Because of the poor alignment of the ITS regions, which are mostly used in the analyses (Fig. 16), we looked at overall sequence similarity rather than evolutionary relationships. However, the maximum parsimony and neighbour-joining bootstrap analyses gave similar results.

\section{Discussion}

The two distinct clades that show up in the analyses were compared with the morphological data. The stalk sclerites, point spindles, and colony form did not yield any clear correlation with the phylogeny found. However, specimens in Clade I, with the exception of the Chromonephthea franseni specimen, showed the characters for Stereonephthya as reported by Utinomy: 1) supporting bundles of the polyps are well developed with strong projecting tip; 2) ventral side of the polyp stalk has small tiny rods; 3 ) polyp heads usually hang down on their stalks, like a campanulate flower; 4) dorsal points strong, ventral points poorly supported or lacking. RMNH Coel. 34814 has both 'campanulatelike' polyps and ones like depicted in figure 12a. The only consistent sclerite character found for clade I is the shape of the rods in the polyp stalks, in this clade they have tiny projections, and are longer (Figs. 13a, $14 \mathrm{a}, 15 \mathrm{a})$ than those in clade II.

The polytomy of RMNH Coel. 34815-16 and RMNH Coel. 32058 in most of the analyses (Fig. 16) confirms the identification of these three specimens based on sclerite characters, which showed them to belong to a single species.

The grouping of Chromonephthea franseni as the sister group next to the Stereonephthya species probably occurred because only one sequence of Chromonephthea was included.

Clade II is a mixture of specimens which, on the basis of the characters used in the classification of Kükenthal, could be placed in Nephthea, Litophyton or Stereonephthya. The Litophyton-like specimen (polyps in catkins, lacking supporting bundle) and the Nephthea-like specimen (polyps in catkins, supporting bundle) group with Stereonephthya-like specimens (projecting supporting bundle, catkins not obvious, tiny rods in the polyp stalk). All species in Clade II lack the long polyp stalk rods with tiny projections.

Obviously, the sclerite character found to support the two different clades is extremely small for separat- ing different genera in nephtheids, and therefore it is not surprising that previous researchers never mentioned it as a character. However, despite the small difference in shape, the polyp stalk rods could have a different origin. In all species included in Clade II the polyp stalk rods seem to be similar to those found in the tentacles and ventral points, while in Clade I they are situated somewhat further apart from the polyp head and are clearly different from the tentacle and ventral point rods. They could represent extremely reduced polyp stalk spindles.

Mcfadden et al. (2006), in their phylogenetic analysis of octocoral genera, used the mitochondrial markers ND2 and MSH combined. They also included specimens of Litophyton, Nephthea and Stereonephthya in their analyses. Like we found with MSH, they also found identical sequences for Litophyton and Nephthea. In their analyses they always found a polytomy of Litophyton/Nephthea, Stereonephthya and a specimen identified as belonging to the Atlantic genus Neospongodes. As the 'Neospongodes' specimen was collected in Darwin harbour the first author contacted one of the authors of McFadden et al., viz. Phil Alderslade (Museum and Art Gallery of the Northern Territory, Darwin, Australia), who informed us that the 'Neospongodes' specimen actually belonged to Chromonephthea. The Litophyton, Nephthea and Stereonephthya specimens used were identified with the same criteria we applied. The findings of McFadden et al. do not contradict ours, but apparently the 18S-ITS1-5.8SITS2-28S marker we used gives more resolution than the combined ND2 and MSH markers.

The results of the present molecular study have consequences for the nephtheid classification. In the morphological revisions under progress Nephthea should be synonymized with Litophyton. All species previously assigned to Stereonephthya and Nephthea should be checked with regards to the shape of the polyp stalk rods.

Moreover, Nephthea savignyi Ehrenberg, 1834, the type species of Dendronephthya, has the sclerite and colony form characters of clade II species and should therefore be transferred to Litophyton, making Dendronephthya a junior synonym of Litophyton.

Finally, in the Atlantic genus Neospongodes the polyp stalk sclerites are similar to those found in clade I (Indo-Pacific Stereonephthya) and, according to the code of nomenclature, this name has preference above Stereonephthya. Unfortunately, no recently collected material of Neospongodes species was available for the present DNA study. 
For the moment, pending the completion of the morphological revisions in progress, we retain to the current classification.

\section{Acknowledgements}

We like to thank B.W. Hoeksema (NNM) for collecting some of the material, the Netherlands Organization for Scientific Research (NWO) and the Schure-Beijerinck-Popping Fonds for funding a journey to Palau for Leen van Ofwegen. M. Slierings (NNM) is thanked for curatorial assistance.

\section{References}

Audouin JV. 1828. Explication sommaire des planches dont les dessins ont été fournis par M.J.C. Savigny, pour l'histoire naturelle de l'ouvrage. Déscription de l'Égypte, publié par les ordres de sa Majesté l'Empereur Napoleon le Grand. Histoire Naturelle 1: 227-244.

Bayer FM, Grasshoff M, Verseveldt J. 1983. Illustrated trilingual glossary of morphological terms applied to Octocorallia. Brill/Backhuys Leiden.

Forskål P. 1775. Descriptiones Animalium - Avium, amphiborum, insectorum, vermium quæ in itinere orientali observavit Petrus Forskål, post mortem auctoris edidit Carsten Niebuhr. København.

Forsman ZH, Hunter CL, Fox GE, Wellington GM. 2006. Is the ITS region the solution to the 'species problem' in corals? Intragenomic variation and alignment permutation in Porites, Siderastrea and outgroup taxa. Proceedings of the $10^{\text {th }}$ international coral reef symposium: 14-23.

France SC, Hoover LL. 2001. Analysis of variation in mitochondrial DNA sequences (ND3, ND4L, MSH) among Octocorallia (= Alcyonaria) (Cnidaria: Anthozoa). Bulletin of the Biological Society of Washington 10: 110-118.

France SC, Hoover LL. 2002. DNA sequences of the mitochondrial COI gene have low levels of divergence among deepsea octocorals (Cnidaria: Anthozoa). Hydrobiologia 471: 149-155.

Kükenthal W. 1903. Uber eine neue Nephthyidengattung aus dem südatlantischen Ocean. Zoologische Anzeiger 26(694): 272-275.
Kükenthal W. 1905. Versuch einer Revision der Alcyonaceen. 2. Die Familie der Nephthyiden. 2 Teil. Die Gattungen Dendronephthya n.g. und Stereonephthya n.g. Zoologische Jahrbücher Abtheilung für Systematik, Geographie und Biologie der Thiere 21(5/6): 503-726.

McFadden CS, Donahue R, Hadland BK, Weston R. 2001. A molecular phylogenetic analysis of reproductive trait evolution in the soft coral genus Alcyonium. Evolution 55: 54-67.

McFadden CS, France SC, Sánchez JA, Alderslade P. 2006. A molecular phylogenetic analysis of the Octocorallia (Cnidaria: Anthozoa) based on mitochondrial protein-coding sequences. Molecular Phylogenetics and Evolution 41: 513-527.

McFadden CS, Hutchinson MB. 2004. Molecular evidence for the hybrid origin of species in the soft coral genus Alcyonium (Cnidaria: Anthozoa: Octocorallia). Molecular Ecology 13: 1495-1505.

Savigny JC. 1809-1817. Description de I'Egypte ou recueil des observations et des recherches qui ont été faites en Egypte pendant l'expédition de l'Armee Francaise. Atlas, natural history, 244 plates.

Swofford DL. 2002. PAUP*: Phylogenetic Analysis Using Parsimony (*and Other Methods), Version 4. Sinauer Associates, Sunderland, MA.

Thompson JD, Higgins DG, Gibson TJ. 1994. CLUSTAL W: improving the sensitivity of progressive multiple sequence alignment through sequence weighting, position specific gap penalties and weight matrix choice. Nucleic Acids Research 22: 4673-4680.

Van Ofwegen LP. 2005. A new genus of nephtheid soft corals (Octocorallia: Alcyonacea: Nephtheidae) from the Indo-Pacific. Zoologische Mededelingen Leiden 79: 1-236.

Verseveldt J. 1966. Biological Results of the Snellius Expedition XXII. Octocorallia from the Malay Archipelago (Part II). Zoologische Verhandelingen Leiden 80: 1-109.

Verseveldt J. 1983. The Octocorallian genera Spongodes Lesson, Neospongodes Kükenthal and Stereonephthya Kükenthal. Beaufortia 33: 1-13.

Utinomi H. 1954. Dendronephthya of Japan, II. New species and new records of Dendronephthya and the allied Stereonephthya from Kii region. Publications of the Seto Marine Biological Laboratory 3(3): 319-338.

Received: 21 March 2007.

Accepted: 15 May 2007. 